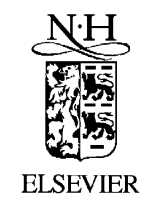

\title{
Securities lending, shorting, and pricing ${ }^{\text {th }}$
}

\author{
Darrell Duffie ${ }^{\mathrm{a}}$, Nicolae Gârleanu ${ }^{\mathrm{c}, *}$, Lasse Heje Pedersen ${ }^{\mathrm{b}}$

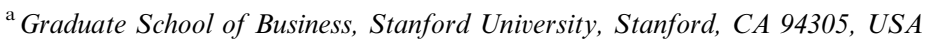 \\ ${ }^{\mathrm{b}}$ Stern School of Business, New York University, New York, NY 10012, USA \\ ${ }^{\mathrm{c}}$ INSEAD, Boulevard de Constance, 77305 Fontainebleau, France
}

Received 27 September 2001; accepted 21 January 2002

\begin{abstract}
We present a model of asset valuation in which short-selling requires searching for security lenders and bargaining over the lending fee. If lendable securities are difficult to locate, then the price of the security is initially elevated, and expected to decline. This price decline is to be anticipated, for example, after an initial public offering, and is increasing in the degree of heterogeneity of beliefs about the future value of the security. The prospect of lending fees may push the initial price of a security above even the most optimistic buyer's valuation of the security's future dividends. A higher price can thus be obtained with some shorting than if shorting is disallowed.
\end{abstract}

(C) 2002 Elsevier Science B.V. All rights reserved.

JEL classification: G12; G14; D83

Keywords: Shorting; Lending fee; Pricing; Differences of opinion

\section{Introduction}

The common method of shorting an equity or a fixed-income security is to borrow the security and sell it. Later, one would buy it in order to return it to the lender,

\footnotetext{
${ }^{2}$ We are extremely grateful for conversations with Jenny Berd, Gary Klahr, and Bryan Schultz of Goldman Sachs, David Modest of Morgan Stanley, as well as Chris Geczy, Bob Jarrow, David Musto, Eli Ofek, Adam Reed, and members of the Standard faculty, especially Anat Admati, Peter DeMarzo, Harrison Hong, Ilan Kremer, David Kreps, John Roberts, and Steve Tadelis, as well as referees and participants at seminar presentations.

*Corresponding author.

E-mail address: nicolae.garleanu@insead.edu (N. Gârleanu).
} 
profiting by any price decline, net of borrowing fees. In some cases, on which we focus, it can be difficult to locate securities available for lending.

We build a dynamic model of the determination of prices, lending fees, and short interest (the quantity of securities held short). Agents trade because of differences of opinions, and would-be shorters must search for security lenders and bargain over the lending fee.

Lending fees are studied in static models by Duffie (1996), Krishnamurthy (2001), and D'Avolio (2001). A key implication of a static analysis and of the fact that, in equilibrium, someone must own the security and not lend it, is that the price is at most as high as the (marginal) valuations of some of the buyers of the asset. In a dynamic economy, on the other hand, we show that the price can initially be higher than the valuations of all investors, ${ }^{1}$ which implies, among other effects, that the price with limited shorting initially exceeds the price with shorting disallowed. The reason behind these results is that an investor is willing to pay more than his valuation, even if he is not immediately lending the security, if he expects to profit from lending it in the future when the opportunity arises. This effect may, under special circumstances, even make the price of a subsidiary larger than the price of its parent firm - that is, generate a negative "stub value."

Our analysis further complements the existing literature by addressing the dynamics of the price, of the lending fees, and of the short interest. The basic intuition for these dynamics can be provided in the context of the following crude, but illustrative, related model. Suppose that 60 optimistic agents assign a value of 100 to a security, that 20 pessimistic investors assign a value of 90 , and that trade and lending transactions occur sequentially, such that the float of 10 shares is shorted in two rounds for a total short interest of 20. (This assumes a position limit of at most one, short or long.) After both rounds of shorting, the lending fee is zero and the price is 100 . Therefore, assuming that the lenders have all of the bargaining power, in the final round of lending, shorters are willing to pay a lending fee of $100-90=10$ for the opportunity to short. Anticipating this lending fee, optimists are willing to buy the asset for $10+100=110$, which is thus the price prior to the last round of lending. Hence, in the first round of lending, shorters are willing to pay $110-90=20$ for the opportunity to short, which implies an initial price of 120 . One sees that, at any point of time, the price is elevated by the remaining number of lending transactions, multiplied by the differences of opinions, $100-90=10$.

Stepping away from this simple illustration, our model studies, with a continuum of potentially different agents, the manner in which the short interest builds up and the valuation of the marginal buyer changes, the impact of bargaining between lenders and borrowers, and the joint determination of prices and lending fees. We find that the short interest increases gradually and the prospective fees from future loans decrease. Empirically, Geczy et al. (2001) indeed find that lending fees are relatively high immediately after an initial public offering (IPO) and on average

\footnotetext{
${ }^{1}$ The opportunity to speculate, when shorting is impossible, can also lead to prices higher than the valuations of all investors, as shown by Harrison and Kreps (1978). See also Morris (1996) and Scheinkman and Xiong (2001).
} 
decline over time, while Ofek and Richardson (2001) find that the level of short interest is positively correlated with the age of the firm, and that lending fees tend to decrease with the age of the firm.

As lending fees decline, so does the valuation of the marginal investor, both effects leading to a decline in the price. Consistent with this, Jones and Lamont (2001) find that, for a sample of NYSE stocks during the period 1926-1933, those with high lending fees tend to have inferior average returns. Our model predicts a relationship between expected returns and lending fees, as opposed to the rather conflicted literature relating returns to the current level of short interest. ${ }^{2}$ Since the lending fees reflect the expectation of future shorting demand, our model suggests that price declines can be more directly related to expected changes in the short interest over time.

Our model also implies that the lending-fee effects are larger with a smaller float, or with larger differences of opinion. The expected price decline associated with lending fees, then, is likely to be more pronounced in situations characterized by a high degree of belief heterogeneity and a small number of circulating shares. Thus, our model is also consistent with low average returns during the period immediately following an IPO ${ }^{3}$ when the heterogeneity of investors' expectations may be highest ${ }^{4}$ and the quantity of shares available for lending may be relatively low, especially until the expiration of lock-up agreements, which contractually delay insider sales. The presence of high lending fees, on its own, could account for a substantial adverse impact on conventional measures of IPO returns. From Fig. 1 of Geczy et al. (2001), for example, the cumulative effect of above-normal securities lending fees for the first six months after an IPO, on average over their sample, amounts to approximately $0.75 \%$ of the market value of the underlying equities. ${ }^{5}$ This implies that an investor who could be assured of placing purchased shares immediately into lending agreements would be willing to accept an average reduction of approximately $1.5 \%$ in annualized expected return over the first six months in return for the lending fees. While there are in fact delays in arranging lending agreements, which is one of the points of our paper, this suggests an impact of securities lending fees on the expected returns demanded of IPOs that is not to be ignored when judging IPO performance in the secondary market. Although not addressing IPOs specifically, Jones and Lamont (2001) suggest that lending fees are insufficient on their own to account for

\footnotetext{
${ }^{2}$ See Aitken et al. (1998), Asquith and Meulbroek (1996), Brent et al. (1990), Danielson and Sorescu (2001a), Dechow et al. (2001), Figlewski (1981), Figlewski and Webb (1993), MacDonald and Baron (1973), Safieddine and Wilhelm (1996), Seneca (1967), and Woolridge and Dickinson (1994). Senchack and Starks (1993) do consider changes, but only to decide whether an unexpected amount of shorting happened or not.

${ }^{3}$ Evidence for long-run IPO underperformance is provided by Ritter (1991), Loughran and Ritter (1995), and others, but has been questioned by Brav et al. (2000) and Eckbo and Norli (2001).

${ }^{4}$ By allowing for the marginal investor's valuation to be too high, our model formalizes the intuition in Miller (1977), modeled previously, in a static CAPM framework, in the presence of exogenous shorting constraints or fixed costs, by Lintner (1969), Jarrow (1980), and Figlewski (1981).

${ }^{5}$ This is based on the information plotted in their figure, and approximate. We do not have the underlying numerical data.
} 
the low average performance of stocks with high lending fees, for their 1926-1933 NYSE data set.

Furthermore, our model may contribute to an understanding of the puzzling price behavior of certain equity carve-outs. For instance, Lamont and Thaler (2001), Mitchell et al. (2001), and Ofek and Richardson (2001) point to spinoffs in which the stub value (the implied market value of the portion of the parent company that is not spun off) can be initially negative, seemingly inconsistent with limited liability and optimizing behavior by agents. A recent extreme example is the spinoff of Palm by 3Com. We show that small, even negative, stub values are implied if two groups of investors hold opposite views about both the spinoff and the stub, and if lendable shares are sufficiently hard to locate. In accordance with our model's predictions, stub values typically increase over time.

We also offer two extensions to the basic model, endogenizing the amount of shorting capital and incorporating delayed settlement.

We abstract from the manner in which information revelation is suppressed by shorting constraints (see Diamond and Verrecchia, 1987), from the potential impact of derivatives trading (which can be viewed as an alternative to shorting, when shorting is costly or constrained), ${ }^{6}$ from the interim risk of hitting margin constraints (see, for instance, Shleifer and Vishny, 1997), and from the risk of early recall.

The remainder of the paper is organized as follows. The next section provides a description of the institutional features of the markets for securities lending and shorting. Section 3 sets up and solves the model, including a characterization of the equilibrium, comparative statics, and a treatment of the impact of delayed settlement. Section 4 applies the model to the behavior of the prices of spinoffs relative to their parent firms. Appendix A shows, as a benchmark, that, without frictions, the unique equilibrium lending fee is zero. Proofs are in Appendix B, while Appendix $\mathrm{C}$ reports the calculations in a parametric setting.

\section{The market for securities lending}

In a typical securities lending transaction, a would-be shorter, such as a hedge fund, would request a "locate" from its broker. The broker might locate the stock in its own inventory, or in the accounts of those of its customers permitting the use of their securities for lending. Failing this, the broker could turn to a custodian bank, or to another potential lender. Natural lenders include institutional investors such as insurance companies, index funds, and pension funds, who tend to have large and long-duration buy-and-hold investments. Brokers may even have exclusive contracts with institutional investors for access to portfolios of securities for lending purposes, as in a recent major exclusive lending deal between Credit Suisse First Boston

\footnotetext{
${ }^{6}$ Empirical investigations of the impact of derivatives trading include Danielson and Sorescu (2001b), Jennings and Starks (1986), Skinner (1990), and Senchack and Starks (1993).
} 
(CSFB) and California Public Employees' Retirement System (CalPERS). ${ }^{7}$ The broker's search for lendable securities might be conducted using an electronic locate system, or by email, fax, or telephone. On May 22, 2001, ten large financial institutions announced the formation of Equilend, an automatic multi-broker lending facility. (Notably, CSFB was not one of the ten initial participating firms.) A Financial Times reporter outlining the proposed role of Equilend described traditional methods for brokering shorts as "labor-intensive, because the appropriate shares or securities can take time to locate." (May 22, 2001, p. 28.)

When encountering stocks that are, using the common industry term, "hard to locate," brokers sometimes cannot "circle" the quantity of lendable shares requested. Brokers may offer "partial fills." Occasionally, a significant amount of time may pass before the necessary stock can be located. (Unfortunately, we do not have data concerning the distribution of time delays for locating lendable stocks.) Factors said to be related to the degree of difficulty of locating lendable shares include the capitalization of the issue, the float (the quantity of shares available for trade), whether the stock is included in an index, the stock's liquidity, the degree of concentration of ownership, and the presence of special activity, such as IPOs, mergers, spinoffs, or acquisitions.

Once a security is located, the broker may execute a "pay-for-hold" transaction, compensating the lender for holding the securities until the borrower executes a short sale. This transaction is sometimes called "pre-borrowing." Trades in the stock itself are normally executed in the US within three days of the trade. Normally, sell orders that are short sales are marked "short" for special attention, because they may be executed only on an "uptick," an SEC regulation.

The actual securities-lending transaction, given a locate, can be accomplished on a same-day basis. If conducted through a broker, the broker would typically act as the borrower from the outside lender, and as the lender to the outside borrower. Cash collateral, normally $102 \%$ of the market value of the borrowed shares for domestic securities (105\% for international securities), is passed from the borrower to the

\footnotetext{
${ }^{7}$ On November 3, 2000, CSFB offered the following press release. "Credit Suisse First Boston (CSFB), in the largest deal of its type, announced today that it has been selected by the California Public Employees' Retirement System (CalPERS) to be an exclusive securities lending principal borrower for CalPERS' passively managed Wilshire 2500 and small-cap stock portfolios totaling more than $\$ 57$ billion in equity assets. In this arrangement, CalPERS has given CSFB the exclusive right to borrow the assets held in each of the portfolios for a guaranteed fee. 'The combination of CalPERS and CSFB in this securities lending relationship will give the System's members superior value for their assets while allowing CSFB to continue expanding its Equity Finance franchise,' said Bob Sloan, Managing Director of the global Equity Finance Group at CSFB. 'This places CSFB in a position to further our franchise in the prime brokerage and alternative capital arena,' he continued. 'We are very pleased CalPERS has selected CSFB.'... eSecLending provided the platform for distributing bidding parameters and guidelines to participating broker/dealers and disseminating bidding results to CalPERS for execution. eSecLending, LLC, (www.eseclending.com), is a new firm offering a web-based auction system for securities lending. The new process is designed to meet the needs of large pension funds, mutual funds and other major investors including online custodians. Burlington, Vt-based eSecLending serves as the primary developer of the web platform and software, and is responsible for staffing and managing the auction process." (Source: www.csfb.com) The term "portfolio valuation" has apparently been used by brokers for the valuation of such exclusive lending rights. We are not aware of the fee in the CalPERS-CSFB deal.
} 
lender in exchange for the shares. The lender "rebates" interest on the collateral at an agreed overnight rate. An overnight rebate rate of $r$ implies a daily interest payment of $r / 360$ times the amount of cash collateral. The interest payments may accrue on a daily basis, for month-end settlement. The rebate offered by the broker to its outside borrower would normally be lower than the rebate received by the broker from its outside lender. The extent to which the rebate is below a market rate (such as the federal funds rate in the United States) represents a benefit to the lender over other sources of funding. Occasionally, other securities are used as collateral, rather than cash, in which case an outright lending fee is charged. Only $1 \%$ of the security loans by a custodian bank appearing in the database analyzed by Geczy et al. (2001) were of this type.

Under SEC Regulation T, shorting retail customers of brokers must, in addition to the cash collateral, post $50 \%$ of the market value of the stock in additional collateral, although this additional collateral may be posted in Treasury Bills. ${ }^{8}$ Shorting retail customers typically do not receive interest on their cash collateral or lending fees because their shares are normally held in street name. Street-name shares are part of the broker's "fungible mass" of shares held at the Depository Trust Corporation. When shares from this fungible mass are lent by the broker, there is nothing that ties the identity of the shares lent to a particular owner, as explained by Apfel et al. (2001).

In this paper we focus (implicitly) on institutional investors. One of the purposes of the paper is to model and present-value the stream of low-rebate benefits to owners of lendable shares. Our results do not attempt to capture the effect of retail owners that are not sufficiently large or sophisticated to enjoy the benefits of lending fees.

Lending agreements are normally on an open or continuing basis, renewed each day with an adjustment of the cash collateral according to changes in the market price of the stock and at a newly negotiated rebate rate. The lender may opt out of a continuing lending arrangement by issuing a recall notice, in which case the borrower must return the stock. A typical method for the short-seller to return the stock would be to borrow it from another lender. Alternatively, the borrower's broker could issue its own recall notice to another borrower. In some cases, called "short squeezes," the borrower (or its broker) is unable to locate lendable shares and is "bought in," that is, must buy the stock outright. ${ }^{9}$ If the borrower fails to deliver the security in standard settlement time, the lender itself may buy it, using the cash collateral. The borrower remains responsible for any additional costs to the lender in conducting the buy-in. With a buy-in, the short sale is effectively interrupted. Institutional investors are viewed as preferred lenders, as they tend to hold stock positions over long periods of time, and are relatively unlikely to recall the stock. An

\footnotetext{
${ }^{8}$ Maintenance margin is $30 \%$, or $\$ 5$ per share, whichever is greater. Investors may short a stock that they already own, a practice called "shorting against the box," for example in order to create the effective reduction in equity exposure associated with a direct sale, but avoid immediate recognition of capital gains for tax purposes. The additional margin required when shorting against the box is only $5 \%$, according to Brent et al. (1990).

${ }^{9} \mathrm{~A}$ broker might, as a service to a highly valued customer, buy the stock on its own account in order to lend it to the customer.
} 
unrelated broker would normally be a less desirable lender, because of uncertain motives for maintaining a position in the stock over time.

During a lending agreement, ownership title (including voting rights and rights to any distributions, including dividends and shares) passes to the borrower. ${ }^{10}$ Cash-inlieu-of-dividend payments are made by the borrower to the lender.

In addition to borrowing for the purpose of profiting from a price decline or to obtain securities to deliver under a prior lending agreement, stocks may also be borrowed in order to hedge an investment (such as an equity derivative or a convertible bond), to gain access to voting rights, or to be the owner of record for dividends, which can be useful for certain accounting or tax reasons, or for dividenddiscount reinvestment plan purchases, the benefits of which are documented by Scholes and Wolfson (1989).

Shares are lent to obtain the cash collateral as a source of financing, to profit from the associated low rebates, or to meet the terms of an exclusive lending agreement, in return for which the lender receives a guaranteed fee, as in the CSFB-CalPERS deal.

\section{Securities lending and asset pricing}

This section contains the basic model, based on trade among agents with divergent beliefs about the prospective future value of an asset. Optimists want to buy the asset; pessimists want to sell it short. The key features of this model are: (i) an agent can sell only owned and borrowed shares, (ii) those wishing to borrow or lend must search for each other, and (iii) the borrower and lender must negotiate a fee. Our valuation approach is based on Duffie et al. (2000), which has a search-andbargaining structure similar to that earlier used in certain monetary models, particularly Trejos and Wright (1995).

\subsection{Model}

Our model addresses a hypothetical asset that pays no dividends before a stopping time $\tau$ with Poisson arrival intensity ${ }^{11} \gamma$. At time $\tau$, the present market value $V$ of the future dividends is revealed to all agents. ${ }^{12}$ Before this "day of reckoning," no information concerning $V$ is revealed. Of the total amount of shares outstanding, the float (amount of actual shares available for trade) is fixed at $F$. By a small adjustment of the model, we could also examine the implications of scheduled changes in the

\footnotetext{
${ }^{10}$ In Japan, given the Japanese tax treatment of dividends, it is common for the lender to recall the stock prior to dividends, in order to be recognized as the holder of record.

${ }^{11}$ We fix a probability space $(\Omega, \mathscr{F}, \mathscr{P})$ and a filtration $\left\{\mathscr{F}_{t}: t \geqslant 0\right\}$ of sub- $\sigma$-algebras, satisfying the usual conditions as defined by Protter (1990), representing the information commonly available to investors. The stopping time $\tau$ is exponentially distributed with mean $1 / \gamma$. The intensity need not be taken constant over time, or even deterministic. The model can also be solved for arrival-time distributions that are not given by intensities.

${ }^{12}$ We may take $V$ is an $\mathscr{F}_{\tau}$-measurable bounded random variable.
} 
float over time, for example through expiration of lock-up agreements, or through merger or spinoff events.

We assume for simplicity that agents are risk-neutral and show no time preference. A continuum of types of agents, indexed by $\sigma \in[0,1]$, agree on the probability distribution of the time $\tau$ at which $V$ is revealed and on the independence of $\tau$ and $V$. They may, however, have different beliefs about the distribution of the eventual value, $V$, of the asset. Specifically, at any time $t<\tau$, an agent of type $\sigma$ expects the value of the asset to be $V^{\sigma}=\mathrm{E}^{\sigma}(V)$, where $\mathrm{E}^{\sigma}$ denotes expectation with respect to the probability measure used by agents of type $\sigma$. Agents' beliefs are common knowledge. The agent types are assumed to be ordered so that, without loss of generality, $V^{\sigma}$ is strictly increasing in $\sigma$. For example, agents of type 1 are the most optimistic; agents of type 0 are the most pessimistic. The masses of the different types of agents are given by a measure $\mu$, in that there is a finite mass $\mu([a, b])$ of agents with a type in an interval $^{13}[a, b]$.

Agents are rational, in the sense that they behave optimally given their beliefs, and update beliefs correctly when receiving information. Morris (1995) argues that differences in priors are consistent with rationality. Further, the assumption of differences of opinions could be exchanged with another (rational) motive for trade. A behavioral interpretation would be that the shorters have "correct" expectations, whereas the optimists are "exuberant." Some "behavioral-finance" papers, for instance, Shleifer and Summers (1990) and DeLong et al. (1990), share the features of differences of opinions and trading frictions.

As a simplification, we assume that each agent can be long or short at most one share. (This can be viewed as an unmodeled substitute for a risk or credit limit, or for the effect of risk aversion.) Trading of the asset takes place as follows. There is a centralized (Walrasian) market for buying and selling shares. At each time $t$, shares can be bought and sold instantly at a price $P_{t}$. In Section 3.7 , we consider the quantitative significance of incorporating a settlement lag, normally three days in the United States, and more in most other countries. (Major brokers in Switzerland obtain same-day settlement.)

In equilibrium, the price $P_{t}$ clears the market. An agent can sell stock, however, if and only if she owns it or has borrowed it. In order to borrow a share, an agent must first find another agent who owns a share that can be lent. Once contact with the lending agent is made, the parties must agree on a borrowing fee before the loan can be executed.

We assume that agents are randomly matched with intensity $\lambda$. That is, given a group of agents with mass $m$, a particular agent finds someone from that group with intensity $\lambda m / 2$, and someone from that group finds that agent with intensity $\lambda m / 2$, for a total contact intensity for that agent of $\lambda m$. This assumption is based, informally at this stage, on an application of the law of large numbers for a "continuum" of agents, as typical in models based on random matching. (Using independent matching, this can be formally justified by taking limits as the

\footnotetext{
${ }^{13}$ The only measurability requirement we have is that intervals are measurable.
} 
number $n$ of agents goes to $+\infty$, with equally likely probability of meeting a particular agent, given a contact. We defer a more careful measure-theoretic treatment of this idealized limiting behavior to other work.) Similarly, agents from a subset of agents of current mass $m_{\mathrm{A}}(t)$ come into contact with agents from a subset of current mass $m_{\mathrm{B}}(t)$ at the total (almost sure) rate $\lambda m_{\mathrm{A}}(t) m_{\mathrm{B}}(t)$. Our model is equivalent to one in which borrowers find other agents with some intensity $\lambda_{\mathrm{B}}<\lambda$, while lenders find other agents with intensity $\lambda_{\mathrm{L}}=\lambda-\lambda_{\mathrm{B}}$. In this sense, borrowers are more effective at searching than are lenders if $\lambda_{\mathrm{B}}>\lambda_{\mathrm{L}}$, but our quantitative results depend only on the total contact intensity $\lambda=\lambda_{\mathrm{B}}+\lambda_{\mathrm{L}}$.

When an agent wishing to short meets an owner of shares, they bargain over the current rate $R_{t}$ at which borrowing fees are paid. These fees are continually renegotiated until either side terminates the contract, so that the total fee paid during an open lending agreement between times $s$ and $t$ is $\int_{s}^{t} R_{u} \mathrm{~d} u$. (The integral makes senses if the borrowing-fee process $R$ is integrable, which is the case in the equilibria that we analyze.) As there is no time preference, credit risk, or risk aversion, if riskfree cash loans were offered in our model, then the market interest rate would be zero, so we can also view $R_{t}$ as the "specialness," that is, the difference between the rebate and the normal short-term interest rate.

For now, we characterize equilibria in which only "pessimists," meaning agents of the lowest-valuation type $\sigma=0$, are permitted to short. In Section 3.6, we show that this restriction is without loss of generality provided there are frictional transactions costs for shorting and a sufficiently large mass of pessimists.

\subsection{General properties of equilibrium}

In this section we derive some general features of the equilibria in the lending market and the spot market.

We assume that, at time zero, the short interest is zero, that is, no shorting has yet happened. Because of the Walrasian market for shares, the float is initially allocated to the most optimistic agents, that is, to a mass $F$ of agents whose valuations are at least as high as that of any agent not initially allocated shares.

Over time, pessimists meet lenders, borrow shares, and shortsell. These shares are bought by successively less optimistic agents. At time $t$, shares are bought by the current "marginal investors," the most optimistic investors who do not already own shares. We are looking for the equilibrium price process, $P(t)$, the equilibrium borrowing fee rate, $R(t)$, and the equilibrium short interest, $S(t)$ (the total amount of shares held short). We may take the commonly available information at time $t$ to be that generated by prices, rebates, revelation of $V$, and by the times of borrowerlender contacts. ${ }^{14}$

\footnotetext{
${ }^{14}$ This means that the information set $\mathscr{F}_{t}$ is that generated by $\left\{P_{s}, R_{s}, V 1_{\{\tau \leqslant s\}}, 1_{\{\phi \leqslant s\}}: \phi \in \Phi, s \leqslant t\right\}$, where $\Phi$ is the set of times at which identified pairs of agents make contact. In the equilibria that we examine, each agent cares only about observation of $\tau, V$, and that agent's own contact times.
} 
At time $t$, the total long interest is $F+S(t)$, and therefore the "next" buyer's (marginal investor's) type $\sigma(t)$ is well defined as $\sigma(t)=\bar{\sigma}(S(t))$, where ${ }^{15}$

$$
\bar{\sigma}(s)=\inf \{\sigma: \mu([\sigma, 1])<F+s\} .
$$

As of time $t$, the quantity $U(S(t))$ of unfilled shorters, that is, the quantity of pessimists who have not already obtained a short position, is

$$
U(S(t))=\mu(\{0\})-S(t),
$$

the total number of pessimists minus the short interest.

The rate $S^{\prime}(t)$ at which the short interest $S(t)$ is building up over time depends on the rate of contact between un-filled shorters and owners of stocks. This total rate of contact is the product of the meeting intensity $\lambda$, the mass $U(S(t))$ of unfilled shorters, and the float $F$. Thus,

$$
S^{\prime}(t)=\lambda F U(S(t)) 1_{\{F+S(t)<\mu((0,1])\}} .
$$

The indicator factor $1_{\{F+S(t)<\mu((0,1])\}}$ allows for the cessation of shorting once all optimists already own shares. This ordinary differential equation (3) determines the equilibrium short interest $S(t)$ and, together with Eq. (1), the equilibrium allocation of the security.

We model the price $P(t)$ and borrowing fee $R(t)$ that apply in the event that $t \leqslant \tau$. The actual price and borrowing fee jump to $V$ and 0 , respectively, on date $\tau$. We analyze only equilibria in which $P(t)$ and $R(t)$ are deterministic.

Since, in equilibrium, a lending agreement is not terminated before $\tau$, risk-neutral investors at any time $t<\tau$ face a borrowing cost equal to the total expected future lending fee $L_{t}$ paid to the lender, from $t$ onwards. Using the fact that $\mathscr{P}(\tau>u \mid \tau>$ $t)=\mathrm{e}^{-(u-t) \gamma}$,

$$
L_{t}=\mathrm{E}_{t}\left(\int_{t}^{\tau} R_{u} \mathrm{~d} u\right)=\int_{t}^{\infty} R_{u} \mathrm{e}^{-(u-t) \gamma} \mathrm{d} u,
$$

where $\mathrm{E}_{t}$ denotes expectation given the information available at time $t$. (This expectation does not depend on type.)

Similarly, for an owner at any time $t$ before $\tau$, the quantity of interest is the expected total income $\mathscr{L}_{t}$ associated with eventually lending the stock, once a borrower is located. This eventual expected income is

$$
\begin{aligned}
\mathscr{L}_{t} & =\mathrm{E}_{t}\left(\int_{T_{L \wedge \tau}}^{\tau} R_{u} \mathrm{~d} u\right) \\
& =\int_{t}^{\infty} \mathrm{e}^{-(s-t) \gamma} \mathrm{e}^{-\int_{t}^{s} \lambda U(S(u)) \mathrm{d} u} \lambda U(S(s)) L(s) \mathrm{d} s,
\end{aligned}
$$

using the fact that $\mathrm{e}^{-\int_{t}^{s} \lambda U(S(u)) \mathrm{d} u} \lambda U(S(s))$ is the conditional density, evaluated at time $s$, of the first time, $T_{L}$, at which a given owner encounters some unmatched pessimist,

\footnotetext{
${ }^{15}$ If the cumulative distribution function of types is strictly increasing and continuous, then the condition $\mu([\bar{\sigma}(s), 1])=F+s$ uniquely defines $\bar{\sigma}(s)$.
} 
given no such contact by time $t$. The lending deal will be conducted at time $s$ only if $V$ remains unrevealed at that time, explaining the factor $\mathscr{P}(\tau>s \mid \tau>t)=\mathrm{e}^{-(s-t) \gamma}$.

At any time $t<\tau$, an (optimistic) agent of type $\sigma$ who has not already bought the security has an expected benefit from buying at some time $u \geqslant t$ of

$$
\mathrm{E}^{\sigma}\left(\left(V+\mathscr{L}_{u}-P_{u}\right) 1_{\{u<\tau\}} \mid t<\tau\right)=\left(V^{\sigma}+\mathscr{L}_{u}-P_{u}\right) \mathrm{e}^{-(u-t) \gamma} .
$$

By the definition of the time- $t$ marginal-investor type $\sigma(t)$, it must be optimal for this type to be ready to buy for the first time at time $t$. For this to be the case, the marginal benefit to this type of waiting, in terms of price reduction net of forgone lending fees, must be equal at time $t$ to the marginal cost of waiting, in terms of the expected rate of loss for this type caused by not having purchased the asset in time to have profited from the expected price change at the day of reckoning, time $\tau$. This expected opportunity-loss rate is the mean arrival rate $\gamma$ of the revelation of $V$, multiplied by the mean expected gain $V^{\sigma(t)}+\mathscr{L}(t)-P(t)$ given prior purchase. That is, we must have the first-order condition

$$
\frac{\mathrm{d}}{\mathrm{d} t}[\mathscr{L}(t)-P(t)]=\gamma\left[V^{\sigma(t)}+\mathscr{L}(t)-P(t)\right]
$$

which is also obtained from Eq. (6) by differentiation with respect to $u$, evaluating the result at $u=t$ and at $\sigma=\sigma(t)$, and finally setting the result equal to zero. We can treat Eq. (7) as a linear ordinary differential equation in $\mathscr{L}(t)-P(t)$, with the solution given by the following result. (The appendix proves global optimality of the solution given by the first order conditions.)

Proposition 1. In any equilibrium, the price, $P$, and the expected revenue, $\mathscr{L}$, from prospective lending fees satisfy

$$
\begin{aligned}
P_{t} & =\mathscr{L}_{t}+\int_{t}^{\infty} V^{\sigma(u)} \mathrm{e}^{-(u-t) \gamma} \gamma \mathrm{d} u \\
& =\mathscr{L}_{t}+\mathrm{E}_{t}\left(V^{\sigma(\tau)} \mid \tau>t\right) .
\end{aligned}
$$

The price, $P$, is therefore the expected future revenue $\mathscr{L}$ associated with the potential to lend the asset, plus the expected valuation of the marginal investor at the day of reckoning, $\tau$, given that $\tau$ has not yet arrived. ${ }^{16}$

This provides a natural relationship between the price, $P$, and the expected potential lending fee, $\mathscr{L}$. In order to identify the price and lending fee separately, one must treat the bargaining game between the borrower and the lender.

\footnotetext{
${ }^{16}$ Another way to see the result, pointed out to us by Peter DeMarzo, is as follows. The decision to buy at $t$ is equivalent to the decision to buy at a price, net of prospective lending fees, of $P_{t}-\mathscr{L}_{t}$. For a given agent, the outcome of buying is equivalent to the outcome of paying a price (net of prospective lending fees) that is higher than the corresponding price at which agent $\sigma(\tau)$ buys. In other words, agent $\sigma(t)$ is effectively competing against a hypothetical agent of uncertain type $\sigma(\tau)$ in a first-price auction. The price bid, net of prospective lending fees, is thus the expected valuation $\mathrm{E}_{t}\left(V^{\sigma(\tau)} \mid \tau>t\right)$ of the hypothetical competing bidder, conditional on agent $\sigma(t)$ winning the auction, using the revenue-equivalence theorem between first- and second-price auctions for a private-value good.
} 


\subsection{Negotiating the lending fee}

In this section, we model the negotiation of the lending fee. We consider a potential lender and borrower who have made contact and must agree on a lending fee $L_{t}$. If the agents agree to transact now, then the lender receives $L_{t}$ and the borrower gets his expected utility from shorting, $P_{t}-L_{t}-V^{0}$. The relative strengths of their bargaining positions depend on their outside options, which we determine next.

If the lender walks away from the negotiations at time $t$, then it expects (in equilibrium) a present value of lending fees of $\mathscr{L}_{t}$ from the next borrower, which is thus its outside-option value. Similarly, the borrower's outside-option value at time $t$ is the expected value associated with finding another lender, which is

$$
\mathscr{B}_{t}=\int_{t}^{\infty} \lambda_{s}^{\mathrm{B}} \mathrm{e}^{-\gamma(s-t)} \mathrm{e}^{-\int_{t}^{s} \lambda_{u}^{\mathrm{B}} \mathrm{d} u}\left(P_{s}-L_{s}-V^{0}\right) \mathrm{d} s,
$$

where $\lambda_{t}^{\mathrm{B}}=\lambda F 1_{\{F+S(t)<\mu((0,1])\}}$ is the intensity with which another lender is located.

Hence, the gain from trade between these agents is

$$
L_{t}+\left(P_{t}-L_{t}-V^{0}\right)-\mathscr{L}_{t}-\mathscr{B}_{t}=G_{t}-\mathscr{B}_{t},
$$

where we have used Proposition 1, and where

$$
G_{t}=\mathrm{E}_{t}(\Delta V(\tau) \mid \tau>t)=\int_{t}^{\infty} \Delta V_{u} \mathrm{e}^{-(u-t) \gamma} \gamma \mathrm{d} u,
$$

with $\Delta V_{t}=V^{\sigma(t)}-V^{0}$. Thus, if the lender has a fraction $q$ of the bargaining power, ${ }^{17}$ then the equilibrium lending fee for a loan in progress is

$$
L_{t}=\mathscr{L}_{t}+q\left(G_{t}-\mathscr{B}_{t}\right) \text {. }
$$

This is an equilibrium outcome of Nash (1950) bargaining, and can be justified by an alternating-offer game with risk of breakdown (Binmore et al., 1986), ${ }^{18}$ or by a simultaneous-offer bargaining game (Kreps, 1990).

Using Eq. (13), Eq. (10) is transformed into a linear ODE in $\mathscr{B}$. Knowing $\mathscr{B}$, one solves Eq. (5), which is a linear ODE for $\mathscr{L}$. This leaves the following calculations.

Theorem 2. Suppose the lender has a fraction $q$ of the bargaining power. Then the expected present value $L_{t}$ of the lending fee paid by the borrower to a lender already contacted at time $t$ is given by Eq. (13), where

$$
\begin{aligned}
& \mathscr{B}_{t}=\int_{t}^{\infty}\left(1-\mathrm{e}^{-\int_{t}^{u}(1-q) \lambda_{z}^{\mathrm{B}} \mathrm{d} z}\right) \Delta V_{u} \mathrm{e}^{-(u-t) \gamma} \gamma \mathrm{d} u \\
& \mathscr{L}_{t}=\int_{t}^{\infty} \mathrm{e}^{-\gamma(s-t)} \lambda_{s}^{\mathrm{L}} q\left(G_{s}-\mathscr{B}_{s}\right) \mathrm{d} s
\end{aligned}
$$

\footnotetext{
${ }^{17}$ The bargaining power $q$ need not be constant over time, but we take it so for simplicity of exposition.

${ }^{18} \mathrm{We}$ have solved an explicit bargaining game (à la Rubinstein) over the total fees paid in expectation, $L$, but we do not report this analysis here. The numerical results imply a value for $q$ that is almost constant and very close to 0.5 .
} 
and $\lambda_{t}^{\mathrm{L}}=\lambda U(S(t))$ is the expected rate at which a lender finds a borrower. The price $P_{t}$ is given by (8). Of all equilibria, that given by $q=0$ has the lowest lending fees $\left(L_{t}=\mathscr{L}_{t}=0\right)$ and prices, while that given by $q=1$ has the highest possible lending fees $\left(L_{t}\right.$ and $\left.\mathscr{L}_{t}\right)$ and prices. ${ }^{19}$

The price and lending fee reflect that a given share can potentially be lent several times in the future. Specifically, Eq. (15) says that $\mathscr{L}$ is product of the lender's bargaining power, $q$, and

$$
\mathrm{E}_{t} \sum_{i=1}^{\infty}\left(G_{T_{i}}-\mathscr{B}_{T_{i}}\right) \operatorname{Pr}\left(T_{i}<\tau\right),
$$

which is the expected sum of the future gains that are generated at the random times $T_{1}, T_{2}, \ldots$ at which a typical share is lent between $t$ and the day of reckoning.

Since the bargaining, as modeled above, takes place over $L_{t}$, one interpretation of $L_{t}$ is a lump-sum lending fee paid if the lending arrangement begins at time $t$, and is to continue until the day of reckoning. This lump-sum payment, however, is consistent with continuous payments at a rate $R_{t}$ that is "renegotiation proof," in the sense that a later bargaining over lending fees will lead to no change in the path of $R$. One obtains $R_{t}$ by differentiating Eq. (4), whence

$$
L_{t}^{\prime}=-R_{t}+\gamma L_{t},
$$

yielding

$$
R_{t}=q \lambda_{t}^{\mathrm{L}}\left(G_{t}-\mathscr{B}_{t}\right)+q\left(\gamma \Delta V_{t}-(1-q) \lambda_{t}^{\mathrm{B}}\left(G_{t}-\mathscr{B}_{t}\right)\right) \geqslant 0 .
$$

Just as is the case with $L_{t}$, the formula for $R_{t}$ highlights that the lending fee is jointly determined by outside options and gains from trade. The first term, $q \lambda_{t}^{\mathrm{L}}\left(G_{t}-\right.$ $\mathscr{B}_{t}$ ), is the outside option of the lender, in a rate sense. The second term is the rate counterpart of the fraction $q$ of the gains available for splitting.

\subsection{Characterizing the prices and lending fees}

In this section, we derive some properties of prices and lending fees that apply in all of the equilibria that we have identified. First, we have some natural time dynamics.

Proposition 3. For $t<\tau$, the expected future borrowing fees $L(t)$ and $\mathscr{L}_{(t)}$, the price, $P(t)$, and the volume of trade, $S^{\prime}(t)$, are all decreasing in $t$. The short interest $S(t)$ is increasing in $t$. As $t \rightarrow \infty$, it holds that $\mathscr{L}(t) \rightarrow 0$ and $P_{t}$ approaches the Walrasian price, $W_{t}{ }^{20}$ Furthermore, if the owners have all of the bargaining power, or if there is no

\footnotetext{
${ }^{19}$ These prices and lending fees are minimal and maximal, respectively, across all possible equilibria, not just within the class of bargaining equilibria considered here.

${ }^{20}$ We define the Walrasian price $W_{t}$ as the highest price for which an equilibrium with a maximal amount of shorting obtains. When the valuation of the marginal investor is unique, only one such price exists and it equals this valuation. See Appendix A for details.
} 
variation among the valuations of the optimists and $\mu(\{0\})<\mu(0,1])$, then $R_{t}$ also decreases.

The intuition behind these results is simple. As time passes, as long as the day of reckoning has not arrived, ${ }^{21}$ agents with a short position maintain their position, while other pessimists meet owners from whom they borrow in order to short. As the short interest increases, the quantity of unfilled shorts is reduced, so that each share is expected to be lent a smaller number of future times. This effect depresses the lending fees, as well as the price with the passage of time. Another effect, working in the same direction, is the diminution of the expected valuation of the marginal investor at $\tau$, the day of reckoning.

Under certain conditions, the instantaneous lending rate $R_{t}$ also decreases over time, reflecting the smaller gains to be made by shorting at later times. The lending rate may, however, increase during certain intervals. ${ }^{22}$

We now compare the equilibrium properties of economies that are distinguished by their parameters. We consider first the dependence of lending fees on the differences of opinions between optimists and pessimists. We say (in the sense of comparative statics) that there is an increased difference of opinions between optimists and pessimists if the pessimists' valuation, $V^{0}$, decreases and if the crosssectional distribution of the optimists' valuations increases in the sense of first-order stochastic dominance (FOSD).

Proposition 4. With any increase in the difference of opinions between optimists and pessimists, there is an increase in the lending fees, $L_{t}$ and $\mathscr{L}_{t}$. With any increase (in the sense of FOSD) in the optimists' valuations, holding constant the pessimists' valuation $V^{0}$, the asset price $P_{t}$ increases.

Increasing the float $F$ has two effects. First, it increases the quantity of agents who can hold the security, both directly, and indirectly by facilitating a more rapid growth in the short interest. Hence, the marginal investor is less optimistic with a larger float. Second a larger float is associated with a reduction in the expected number of times that a given share will be lent. Both of these effects reduce the price and the expected lending fee, as stated below. This result may partially address the influence of a small float on the initial valuation of IPOs, fixing the fundamentals and the total number of shares outstanding,

\footnotetext{
${ }^{21}$ We make no statement regarding the expected changes of the price, taking into account the jump at the reckoning day, since we do not impose any restrictions on the actual distribution of the value of the asset.

${ }^{22}$ Intuitively, $R_{t}$ can increase if the outside option of the borrower decrease sufficiently faster than that of the lender. In that case, relatively to the borrower, the lender is keener on agreeing on a transaction now, and willing to accept lower rates. Due to the fact that both options, in a rate sense, are multiples of the gains from trade $G_{t}-\mathscr{B}_{t}$, the condition translates into requiring a higher outside option for the borrower, and a sharp decrease in $G_{t}-\mathscr{B}_{t}$. Imposing $q=1$ makes the outside option of the borrower 0 , while a two-point distribution of agents' valuations with more optimists than pessimists makes $G_{t}-\mathscr{B}_{t}$ constant, whence the two alternate sufficient conditions in the statement of the proposition.
} 
Proposition 5. The price, $P_{t}$, and the lending fees, $L_{t}$ and $\mathscr{L}_{t}$, are decreasing in the float, $F$, and increasing in the lender's bargaining power, $q$.

Increasing the search intensity $\lambda$ or increasing the initial quantity $\mu(\{0\})$ of wouldbe shorters, which we may think of as proportional to the amount of capital available for shorting, decreases the valuation of the marginal investor, pushing down the price and the lending fee. At the same time, however, it increases the expected number of times that a given share can be lent, which on its own would increase the lending fee and hence the price. Changes in these quantities also alter the bargaining positions of the two parties.

Proposition 6. The price, net of expected future lending fees, $P-\mathscr{L}$, decreases with $\lambda$ and with $\mu(\{0\})$, and increases with $\gamma$. Separately, though, the price $P$ and the prospective expected lending fee $\mathscr{L}$ need not be monotonic in $\lambda, \mu(\{0\})$, or $\gamma^{23}$

Of particular interest is that, as the meeting intensity $\lambda$ goes to infinity, the price $P_{t}$ approaches the perfect-market (Walrasian) price $W_{t}$, defined precisely in Appendix A.

Proposition 7. Suppose the lender's bargaining power $q$ is strictly less than 1. Then, as the search intensity $\lambda$ tends to infinity, for all $t$, the expected future lending fees $L_{t}(a t$ the time of a loan) and $\mathscr{L}_{t}$ (when searching for a loan) tend to zero, and the price $P_{t}$ tends to $W_{t}{ }^{24}$

The intuition behind this result is the following. Assume first that there are not enough pessimists to satisfy, via shorting, the entire optimistic demand for the asset. Then, as $\lambda$ gets large, while pessimists find it easier and easier to meet a potential lender, lenders are faced with a rapidly diminishing pool of agents to whom they may lend. This induces lenders without full bargaining power $(q<1)$ to agree to fees that decrease to zero. On the other hand, with a large quantity of pessimists, the marginal investor's valuation quickly approaches that of a pessimist, leaving no gains from lending.

In the complementary situation, in which lenders have perfect bargaining power $(q=1)$, as of time zero, the potential expected gain from lending an asset repeatedly until the day of reckoning all accrue to the owner at time zero. This expected gain is the expected number of times that the asset is expected to be lent, multiplied by the difference in valuation between the marginal investor and the pessimist. In the limit as $\lambda$ gets large, the asset is lent the maximum possible number of times,

$$
\beta=\frac{1}{F} \min \{\mu(\{0\}), \mu((0,1])-F\} .
$$

We can summarize this case as follows.

\footnotetext{
${ }^{23}$ Our numerical example, in Section 3.5, illustrates the non-monotonicity.

${ }^{24}$ See footnote 20 and Appendix A.
} 


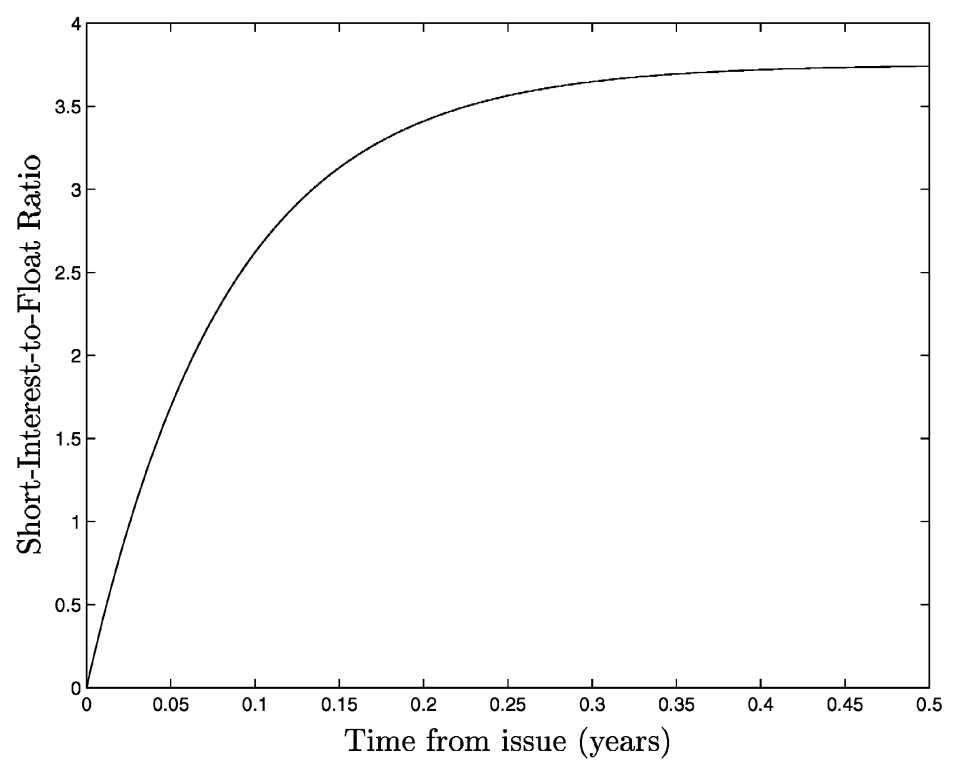

Fig. 1. Evolution of the short interest over time. The short interest, $S_{t}=\mu(\{0\})\left(1-\mathrm{e}^{-\lambda F t}\right)$, is scaled by the float. Parameters are $\mu(\{0\})=0.3, \lambda=150$, and $F=0.8$.

Proposition 8. Suppose that the lender has all bargaining power $(q=1)$. Then

$$
\begin{aligned}
& \lim _{\lambda \rightarrow \infty} \mathscr{L}_{0}=\beta\left(W_{0}-V^{0}\right), \\
& \lim _{\lambda \rightarrow \infty} P_{0}=W_{0}+\beta\left(W_{0}-V^{0}\right) .
\end{aligned}
$$

Furthermore, for $t>0$, in the limit as $\lambda \rightarrow \infty$, we have $\mathscr{L}_{t}=0$ and $P_{t}=W_{t}$.

\subsection{Numerical example}

We illustrate with an example. As our base case, we assume that there is a mass $\mu(\{0\})=0.3$ of pessimists whose personal valuation of the asset is $V^{0}=100$, while the valuations of optimists, of total mass $\mu((0,1])=3$, are uniformly distributed between $V^{0}$ and $V^{1}=110$. The float is $F=0.08$.

We first compute the Walrasian price with these investor characteristics. With perfect markets for buying and shorting the asset, all pessimists short. Hence, the total supply is $0.08+0.3=0.38$. This implies a market-clearing price of $W_{0}=108.73$. The Walrasian lending fee is zero, because if it were positive, then the supply of lendable shares would by 0.38 , whereas the demand for borrowing would be 0.3 .

To capture the effect of search frictions in the securities lending market, we assume that the meeting intensity of agents is $\lambda=150$. This means that a shorter looking for an asset to borrow expects to find an optimistic agent after a fraction $1 /(3 \times 150)$ of a 


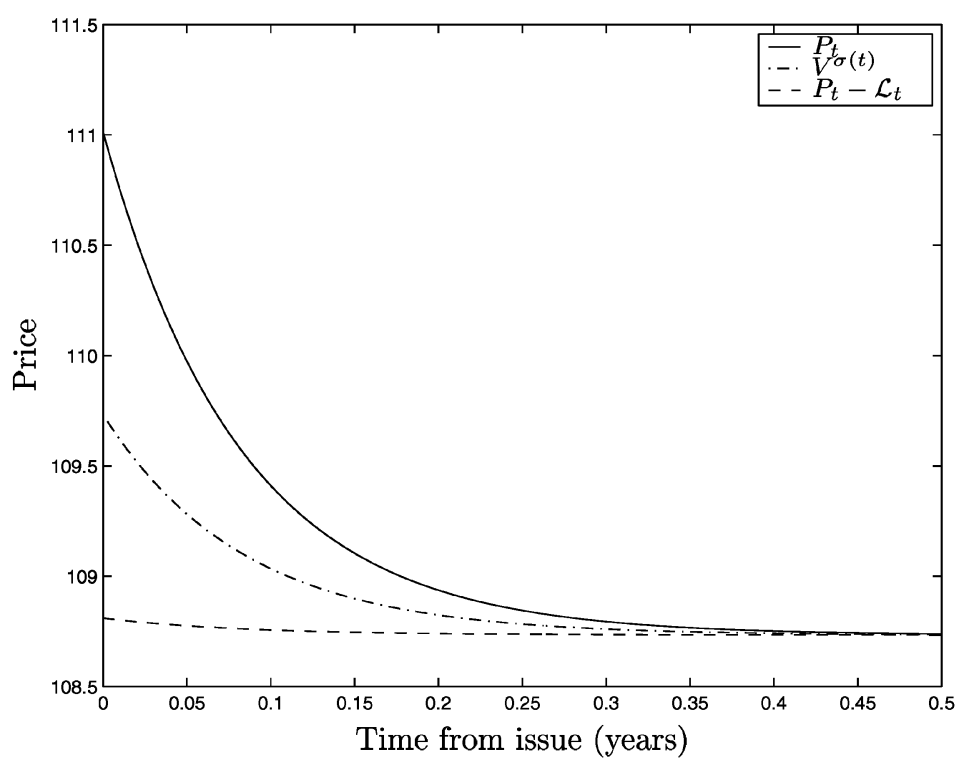

Fig. 2. Dynamics of the price, the marginal investor's valuation, and the price net of lending fees. The explicit formulae are provided in Appendix C.

year, that is, within about half a business day. The shorter only finds an optimistic agent who actually owns a share, though, after an expected fraction $1 /$ $(0.08 \times 150)=1 / 12$ of year, which is about a month. The disagreement between agents regarding the prospects for the stock is expected to continue for one year, in that $\gamma=1$. Shorters and lenders have equal bargaining powers, in the sense that $q=0.5$.

With this specification, the equilibrium can be solved explicitly. (The full solution is provided in Appendix C.) As shorters find lenders, the short interest grows, and by time $t$ is $S_{t}=\mu(\{0\})\left(1-\mathrm{e}^{-\lambda F t}\right)$, using (3). The evolution of the short interest is shown is Fig. 1.

The long interest, $F+S_{t}$, grows with the short interest. The marginal investor is thus sliding down the demand curve. In a world with zero lending fees, the price at time $t$ would be the expected valuation at the reckoning day, $\mathrm{E}\left(V^{\sigma(\tau)} \mid t<\tau\right)$ (Proposition 1), shown as the dashed line in Fig. 2. We note that this price is lower than the valuation of the marginal investor (drawn in Fig. 2 with a dashes-and-dots line) because agents anticipate that the supply is increasing over time. The difference, $V^{\sigma(t)}-\mathrm{E}\left(V^{\sigma(t)} \mid t<\tau\right)$, is the expected profits that optimists get from the ability to time their purchasing decision optimally. At time zero, for instance, the valuation of the marginal investor is 109.73 and the price net of lending fees is 108.81 . As time passes, both the price net of lending fees and the valuation of the marginal investor decrease, approaching their common limit, 108.73. The price net of lending fees decreases because the expected total amount of shorting before the reckoning day increases, 


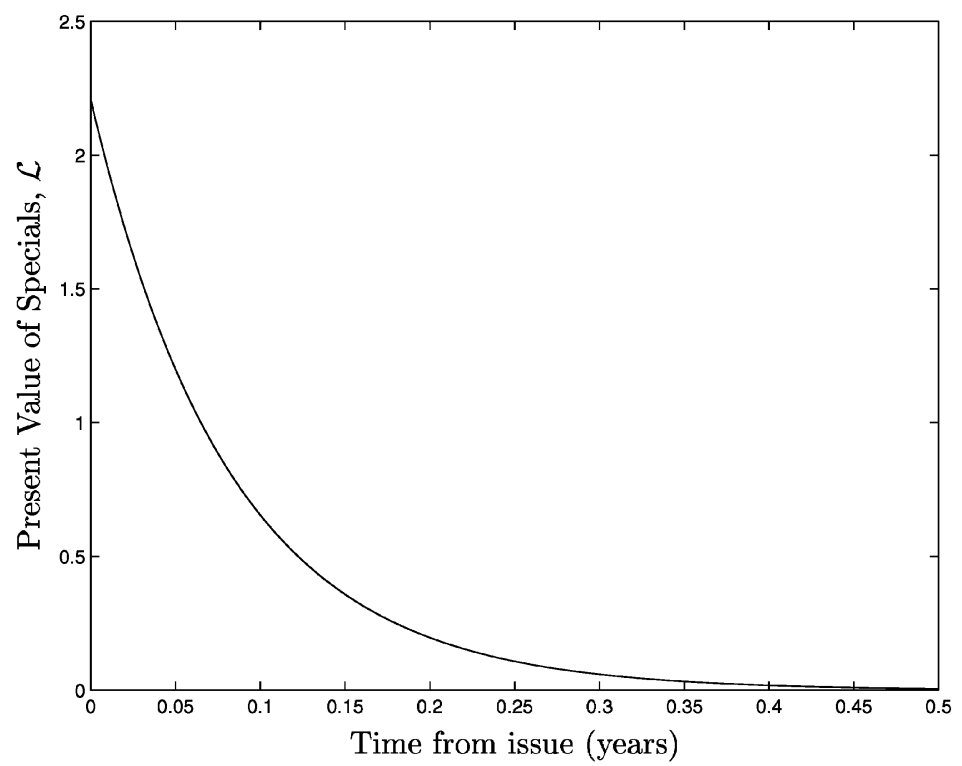

Fig. 3. Dynamics of the prospective lending fee, $\mathscr{L}$. This is the total amount expected to be received as lending fees in the future by an owner who has not found a borrower yet. The explicit formula is provided in Appendix C.

implying a lower expected marginal-investor valuation at $\tau$, but for these parameters this effect is small.

The price, also depicted in Fig. 2, is elevated because agents are willing to pay a premium associated with lending fees. While a buyer cannot lend his share immediately, he expects to profit from lending his share when he is eventually matched with a shorter. The price is thus the sum of $\mathrm{E}\left(V^{\sigma(t)} \mid t<\tau\right)$ and the expected total lending fee $\mathscr{L}_{t}$, which is shown in Fig. 3.

The total lending fee is essentially equal to the gains from a lending transaction, multiplied by the number of times a given share is lent, and further multiplied by the lenders' bargaining power. Eq. (15) makes this intuition precise by taking into account the fact that the gains from lending are changing over time. The number of times a share is expected to be lent is $\int_{t}^{\infty} \mathrm{e}^{-\gamma(s-t)} \lambda_{s}^{L} \mathrm{~d} s$, while the expression for gains from lending at time $t$ is given in the appendix. At time 0 , the expected number of times a share is lent is 3.46. The long-term expected gain from lending (the first term in Eq. (C.3) in Appendix C) is 1.25, explaining the initial expected lending fee $\mathscr{L}_{0}=$ $2.21 \cong 3.46 \times 1.25 \times 0.5$.

The initial total prospective lending fee, $\mathscr{L}_{0}$, represents a price premium at time zero of approximately $2 \%$, enough to make the price higher than the marginal valuation of even the most optimistic investor. The lending-fee price premium decreases to practically zero within six months. We note that the maximal premium, for the case in which lenders have all of the bargaining power, is about $28 \%$ $\left(P_{0}=139.2\right)$. The size of this maximal lending fee can be understood in light of the 


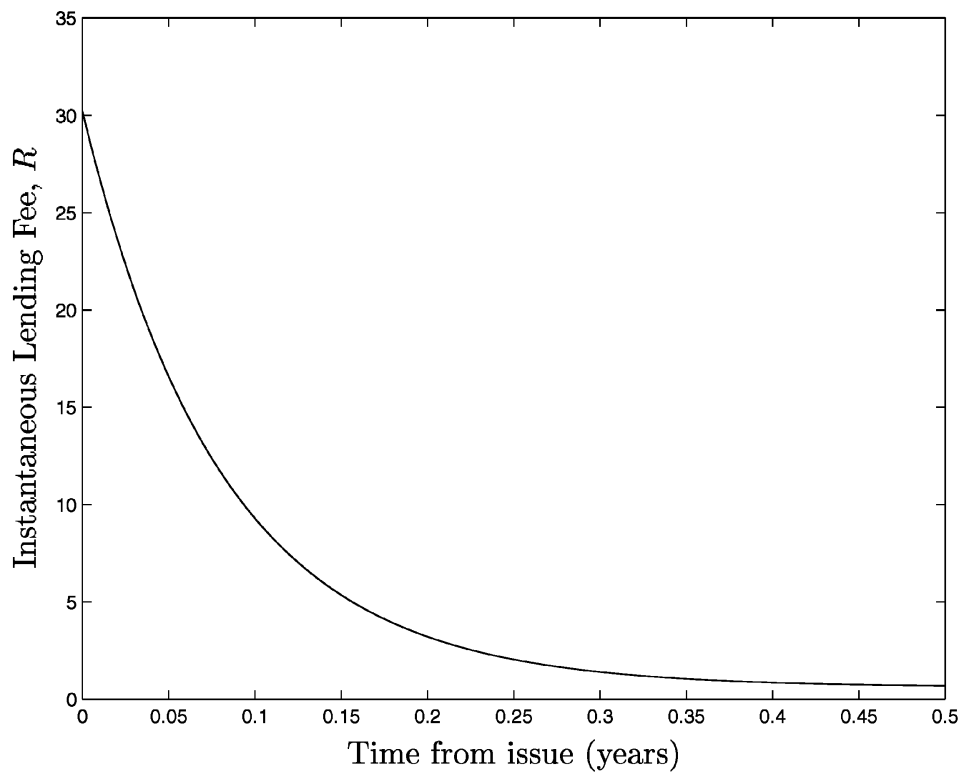

Fig. 4. Dynamics of the instantaneous lending fee, $R_{t}$. The explicit formula is provided in Appendix C.

intuition above. At time zero, each share is expected to be lent 3.46 times, and the expected gains from lending are about $8.7,{ }^{25}$ implying a total expected lending fee of about $30 \cong 3.46 \times 8.7 \times 1$. At time zero, a share will be bought by an agent willing to pay 108.8 plus the expected lending fee received when the owner is matched with a shorter.

The instantaneous lending rate, $R_{t}$, is shown in Fig. 4. The lending rate starts high, at $R_{0}=30.2$, but the exponential decay of the mass of unfilled shorters causes $R_{t}$ to decrease rapidly. Significant specialness can subsist longer if, for instance, search is difficult or if new shorters enter the market gradually over time. While the latter is outside the scope of this paper, we note that Eq. (17) shows that $R_{t}$ could increase in $t$ with a significant inflow of shorting capital.

Examining the dependence of the price on some parameters (in the sense of comparative statics) provides a nice opportunity to further explain the intuition of the model. Fig. 5 plots the price at time zero as a function of the meeting intensity $\lambda$ and the float $F$. When $\lambda=0$, shorting is impossible and the price is the valuation of the marginal investor with a fixed asset supply equal to the float $F$. As $\lambda$ goes to infinity, however, the price approaches the valuation of the marginal investor with the maximal asset supply of $F+\mu(\{0\})$. The intermediate behavior of the price is explained as follows. As lending becomes possible ( $\lambda$ increases from zero), lending fees are incorporated into the price, which rises. The price consequently increases,

\footnotetext{
${ }^{25}$ The gains from trade increase in $q$, since a higher bargaining power for the lender means a lower outside option, forgone when sealing an agreement, for the borrower.
} 


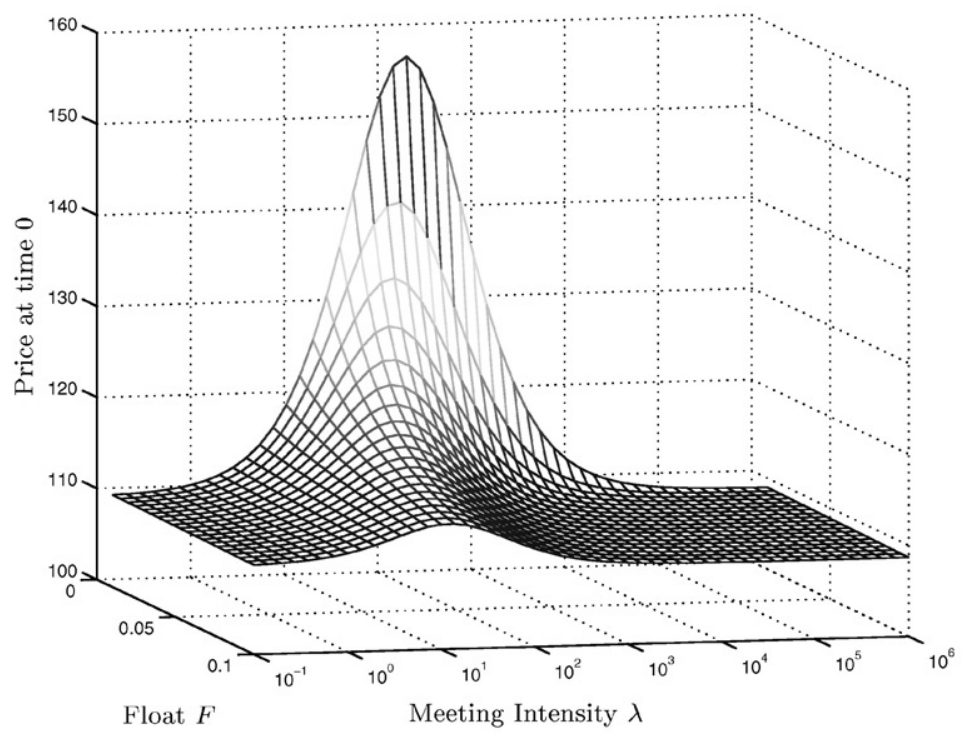

Fig. 5. Price at time $0, P_{0}$, as a function of the meeting intensity, $\lambda$, and the float, $F$. The explicit formulae are provided in Appendix C.

initially, as $\lambda$ becomes larger. Eventually, though, the bargaining position of lenders worsens, due to the rapid reduction in unfilled shorting demand. The lending fees and prices diminish. Fig. 5 also illustrates that the price decreases in the float. A higher float leads to lower prices in part because shares are easier to find and every share is expected to be lent fewer times, resulting in lower lending fees. There is an additional reduction in price from the fact that the marginal investor's valuation, at any time, is lower.

Finally, Fig. 6 illustrates the dependence of the price on the capital available for shorting, at various points in time. At time zero, as $\mu(\{0\})$ grows from zero and shorting takes place, the expected lending fees increase from zero, bringing the price up. Eventually, though, the marginal investor's valuation and the shorters' bargaining power deteriorate sufficiently to diminish the price. At later points in time, much of the shorting has already happened, whence the decreasing price profile in $\mu(\{0\})$.

Whereas a common wisdom states that shorting lowers prices, Figs. 5 and 6 show that initially prices can be non-monotonic in the ease $(\lambda)$ of shorting and in the amount $(\mu(\{0\}))$ of capital for shorting.

\subsection{The equilibrium amount of shorting capital}

Now we consider the endogenous determination of the amount of capital that is made available for shorting. We assume that there is some fixed frictional cost, $c$, of attaining the ability to short. Only agents who have incurred this cost are in a 


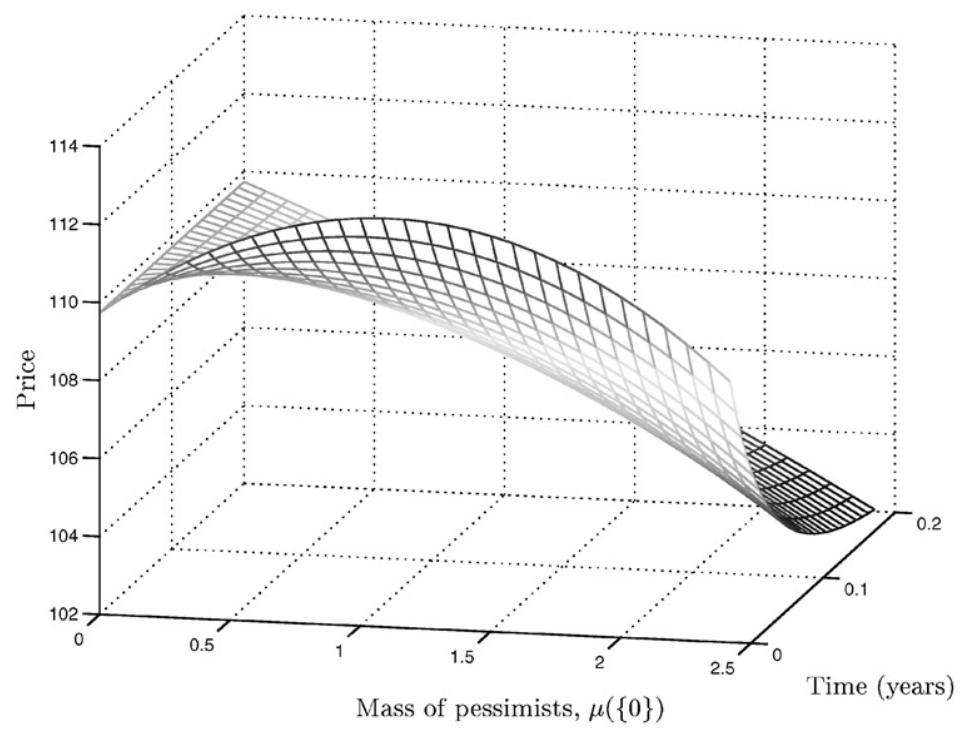

Fig. 6. Price as a function of the mass of pessimist present in the market, $\mu(\{0\})$, at time. The explicit formulae are provided in Appendix C.

position to search for opportunities to borrow shares. The value $\mathscr{B}_{t}$ to a pessimist of acquiring this ability, in the equilibrium of Section 3.3, is characterized as follows.

Proposition 9. At any time $t<\tau$, the expected value, $\mathscr{B}_{t}$, to a pessimist associated with the opportunity to be a shorter (i) decreases with $t$, (ii) is decreasing and continuous in the quantity, $\mu(\{0\})$, of pessimists, and (iii) tends to zero as $\mu(\{0\})$ increases to infinity. If the marginal-type function $\bar{\sigma}(\cdot)$ defined by (1) is strictly decreasing ${ }^{26}$ at zero, then $\mathscr{B}_{0}$ is strictly decreasing in $\mu(\{0\})$.

This result provides for a determinate endogenous level of capital for shorting, in the following sense. Suppose there is an unlimited pool of pessimists that consider the opportunity to incur the entry $\operatorname{cost} c$. At time zero, given the properties stated by the proposition and provided that $c$ is strictly less than the benefit level $\mathscr{B}_{0}$ associated with no pessimists $(\mu(\{0\})=0)$, there is a unique quantity $\mu(\{0\})$ of pessimists that actively seek short positions with the property that the benefit $\mathscr{B}_{0}$ precisely justifies the cost $c$. In equilibrium (of the entry game that we do not formally model here), this quantity $\mu(\{0\})$ of pessimists enters, and is indifferent to doing so, because $\mathscr{B}_{0}=c$. As the benefit $\mathscr{B}_{t}$ decreases with $t$, those entering at time zero correctly anticipate that there is no subsequent entry. With this equilibrium entry of pessimists, no optimist would short, as the expected profit to an optimist from

\footnotetext{
${ }^{26}$ This means that there exists no $\varepsilon>0$ such that $\bar{\sigma}(\varepsilon)=\lim _{S \rightarrow 0} \bar{\sigma}(S)$. (For this condition to hold, it suffices that the distribution of types have a positive density.) If this is not the case, then we obtain the weaker result that $\mathscr{B}_{0}$ is constant for $\mu(\{0\})$ in a set $[0, \bar{\mu}]$ with $\bar{\mu}>0$, and strictly decreasing for $\mu(\{0\})>\bar{\mu}$.
} 
shorting is smaller than that of a pessimist, who in equilibrium is indifferent to entering.

Thus, under these conditions, as anticipated with our initial model, only pessimists (type-0 agents) would choose to sell short. The expected profit from shorting depends on the differences of opinions, as stated below.

Proposition 10. The equilibrium amount, $\mu(\{0\})$, of capital available for shorting increases with an increase in the difference of opinions between optimists and pessimists.

The quantity $\mu(\{0\})$ of those actively seeking short positions depends ambiguously on other model parameters. For instance, a decrease in the float $F$ leads to a higher valuation by the marginal investor, making shorting more attractive, but also makes it harder to find shares to short.

If there were a limited pool of pessimists, agents of different valuation types would acquire the ability to short. Of these, relatively more optimistic shorters could wait until the price declines sufficiently to justify closing their short positions and forming long positions instead. We have avoided the calculation of an equilibrium for this, more complicated, situation.

\subsection{Delayed settlement}

We have so far assumed instantaneous settlement of trades. In many markets, however, settlement occurs with a lag. In most US equity markets, for instance, settlement is " $t+3$," meaning three days after the transaction date, while the market for securities lending is normally based on same-day settlement. Thus, the "spot market" for equities is, in effect, actually a three-day forward market. It follows that if $\mathrm{X}$ sells a share to $\mathrm{Y}$ today, then $\mathrm{Y}$ could not begin lending the share until three days from now.

In this section, we present a simple extension of our model that captures the notion of delayed settlement. We denote the settlement lag by $\theta$. We assume for simplicity that when a share is sold, but has not yet been delivered, it is not available for lending to anyone. In the example above, this means that, during the settlement period, neither $\mathrm{X}$ nor $\mathrm{Y}$ may lend the share sold to $\mathrm{Y}$.

With a settlement lag, the number of shares (potentially) available for lending is a time-varying process, which we denote by $A$. The basic ordinary differential equation (3) determining the short interest $S(t)$ is now replaced by the system of equations ${ }^{27}$

$$
\begin{aligned}
& S^{\prime}(t)=\lambda A(t) U(S(t)) 1_{\{F+S(t)<\mu((0,1])\}}, \\
& A^{\prime}(t)=-S^{\prime}(t)+S^{\prime}(t-\theta),
\end{aligned}
$$

the second of which reflects the fact that the quantity $A(t)$ of shares available for shorting is reduced by the current volume of shorting and increased by newly delivered shares (those that were borrowed and sold $\theta$ units of time ago).

\footnotetext{
${ }^{27}$ At $t=0$, the derivatives involved are derivatives from the right.
} 
With delayed settlement, our model captures a sense in which a security can become harder to locate. A shorter locates a share with intensity $\lambda A(t)$, which is low if the number, $A(t)$, of shares available for shorting is low. This happens, for instance, if there is a large number of agents who want to short, or if there is a long settlement period. (The model can, indeed, produce cyclical variation in the number of shares available for shorting.)

Proposition 11. An increase in the settlement lag $\theta$ causes a reduction in the short interest $S(t)$ for all $t$.

The expected lending fee for a prospective loan, for an agent buying a security at time $t$ with a settlement delay of $\theta$, is $\mathrm{e}^{-\gamma \theta} \mathscr{L}_{t+\theta}$, where $\mathscr{L}$ is defined by Eq. (5). As a consequence, the price is

$$
P_{t}=e^{-\gamma \theta} \mathscr{L}_{t+\theta}+\int_{t}^{\infty} V^{\sigma(u)} \mathrm{e}^{-(u-t) \gamma} \gamma \mathrm{d} u,
$$

modifying Proposition 1 . One can separately compute the price and the lending fee in light of delayed settlement, solving the bargaining game with an arbitrary sharing of bargaining power. ${ }^{28}$

We demonstrate the quantitative effect of delayed settlement by extending the example considered previously. We assume a settlement lag of $\theta=0.012$ (approximately three working days). Figs. 7 and 8 show the price and short interest, respectively, with both instantaneous and delayed settlement. For the parameters chosen, delayed settlement results in a higher present value of the opportunity to lending.

\section{Example: equity carve-outs}

The "strange" behavior of the prices of certain equity carve-outs has received recent attention (Lamont and Thaler et al., 2001; Mitchell et al., 2002; Ofek and Richardson, 2001). For instance, 3Com, which owned Palm, made an initial public offering of about 5\% of Palm shares on March 2, 2000, and promised to later distribute the remaining Palm shares to $3 \mathrm{Com}$ shareholders (conditional on IRS approval of certain tax advantages). The stub value of $3 \mathrm{Com}$, its total market valuation net of the market value of its holdings of Palm, became negative on the first

\footnotetext{
$$
L_{t}=\mathscr{L}_{t}+q\left(G_{t}-\mathscr{B}_{t}-\left(\mathscr{L}_{t}-\mathrm{e}^{-\gamma \theta} \mathscr{L}_{t+\theta}\right)\right),
$$

and $\mathscr{L}$ and $\mathscr{B}$ satisfy the differential equations:

$$
\begin{aligned}
& \mathscr{B}_{t}^{\prime}=-(1-q) \lambda_{t}^{\mathrm{B}}\left(G_{t}-S_{t}-\left(\mathscr{L}_{t}-\mathrm{e}^{-\gamma \theta} \mathscr{L}_{t+\theta}\right)\right)+\gamma \mathscr{B}_{t}, \\
& \mathscr{L}_{t}^{\prime}=-q \lambda_{t}^{\mathrm{L}}\left(G_{t}-\mathscr{B}_{t}-\left(\mathscr{L}_{t}-\mathrm{e}^{-\gamma \theta} \mathscr{L}_{t+\theta}\right)\right)+\gamma \mathscr{L}_{t},
\end{aligned}
$$
}

${ }^{28}$ With delayed settlement, the gain from trade is $G_{t}-\mathscr{B}_{t}-\left(\mathscr{L}_{t}-\mathrm{e}^{-\gamma \theta} \mathscr{L}_{t+\theta}\right)$. Thus,

where $\lambda_{t}^{\mathrm{L}}=\lambda U(S(t))$ and $\lambda_{t}^{\mathrm{B}}=\lambda A_{t}$. 


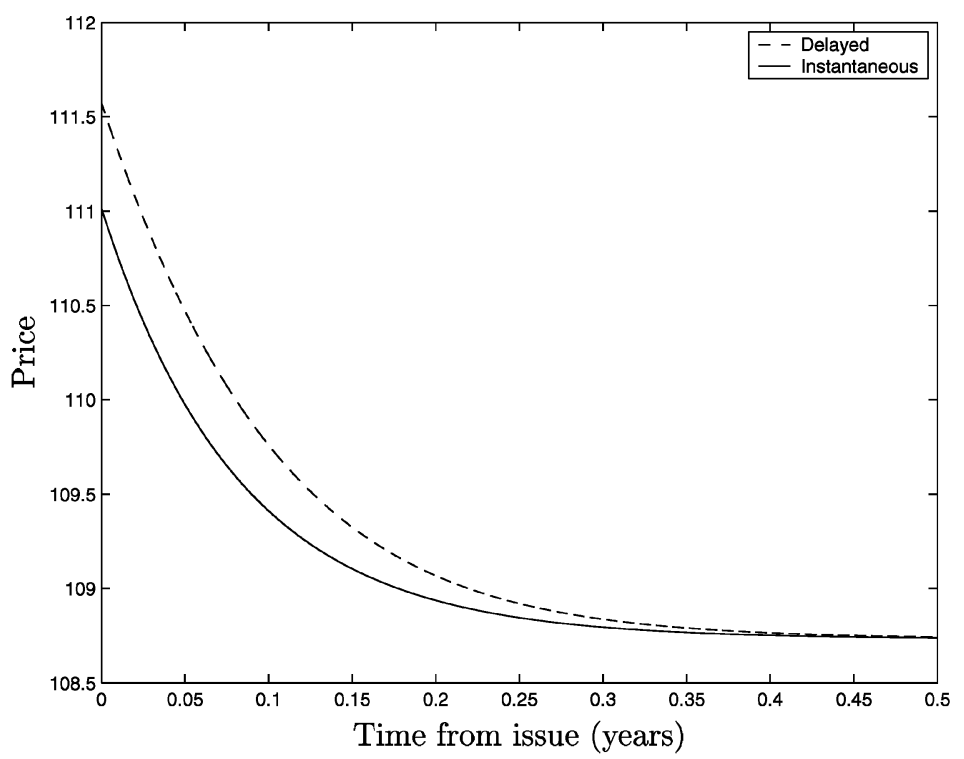

Fig. 7. Price with both delayed and instantaneous settlement. For the delayed settlement case, a numerical method is employed.

day of trading of Palm! This is, at least superficially, at odds with the absence of arbitrage and the limited liability of equities. We now illustrate how our modeling approach allows for the possibility of negative stub values, with no arbitrage and with optimizing agents.

We adopt the following stylized model. Firm A consists of two subsidiaries, B and C. The holding firm A and its subsidiary B are traded on an exchange. We assume for simplicity that each investor can buy or shortsell at most one share of A and one share of $\mathrm{B}$. There is a unit mass of shares of each of $\mathrm{A}$ and $\mathrm{B}$, and the same floats for $\mathrm{A}$ and B. Hence, we can use the model of Section 3 for both A and B. The personal valuations of $\mathrm{A}, \mathrm{B}$, and $\mathrm{C}$ of an agent of type $\sigma$ are denoted by $V^{\mathrm{A}, \sigma}, V^{\mathrm{B}, \sigma}$, and $V^{\mathrm{C}, \sigma}$, respectively, and are assumed to be non-negative and to satisfy $V^{\mathrm{A}, \sigma}=V^{\mathrm{B}, \sigma}+V^{\mathrm{C}, \sigma}$. We are interested in the price $p^{\mathrm{A}}$ of $\mathrm{A}$, the price $p^{\mathrm{B}}$ of $\mathrm{B}$, and the stub value, $p^{\mathrm{A}}-p^{\mathrm{B}}$.

Suppose, first, that all agents agree on the valuation of $\mathrm{C}$, in that $V^{\mathrm{C}, \sigma}=V^{\mathrm{C}}$ for all $\sigma$. In this case, if the two markets work identically, meaning that $\lambda$ and $q$ for $\mathrm{A}$ are the same as the corresponding parameters for $\mathrm{B}$, then the stub value is, naturally, $p^{\mathrm{A}}-p^{\mathrm{B}}=V^{\mathrm{C}} \geqslant 0$.

A negative stub value can arise, however, under certain (rather special) circumstances. For instance, suppose there are two groups of agents, one of which is optimistic about $\mathrm{B}$ and pessimistic about $\mathrm{C}$, relative to the other group. For a numerical example, suppose that investors of type 1 have expected valuations of $B$ and $\mathrm{C}$ of 85 and 15 , respectively. Type- 0 investors have expected valuations of $\mathrm{B}$ and $\mathrm{C}$ of 65 and 35, respectively. All agents thus agree on a valuation of 100 for the holding firm A, which is its equilibrium price. Type-1 agents buy the shares of B; 


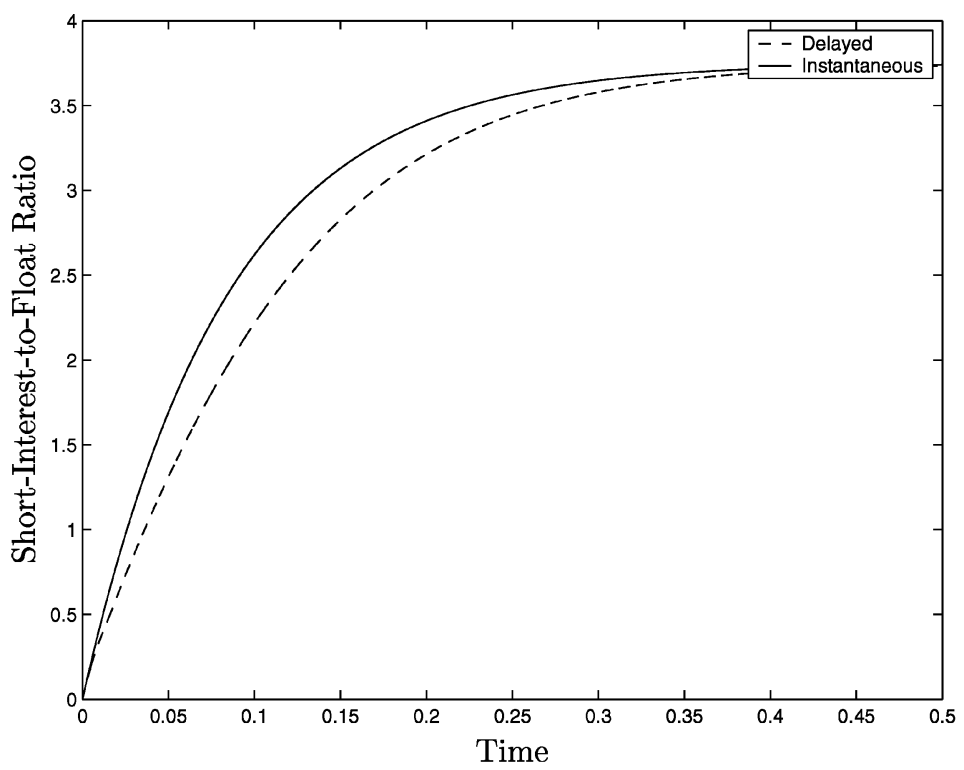

Fig. 8. Short interest with both delayed and instantaneous settlement. A numerical method is employed to solve Eqs. (21) and (22).

Type- 2 agents attempt to short the shares of $\mathrm{B}$. With a contact intensity of $\lambda=100$, a float of $F=0.1$, masses 1 of Type- 1 investors and 0.3 of type- 2 investors, an arrival intensity of $\gamma=5$ for the time at which the valuations of $\mathrm{B}$ and $\mathrm{C}$ are revealed, and a large lender bargaining power $(q=0.9)$, our results imply that the market price of B at time zero is 115.9. The dramatic price effect owes significantly to the large bargaining power of the lender (a maximal price of 133 is obtained for $q=1$ ). Significant price effects are also found with a large amount of shorting capital relative to shares available for lending (that is, the ratio $\mu(\{0\}) / F$ ), and with a large divergence of opinions.

Figure 9 shows that, as the short interest builds up, the stub value increases and eventually turns positive. This pattern is consistent with the empirical observations of Lamont and Thaler (2001), Mitchell et al. (2002), and Ofek and Richardson (2001).

This example shows that a negative stub value is not necessarily inconsistent with optimizing behavior by all agents. An argument for irrationality is proposed by Lamont and Thaler (2001), who write: "It is always true that someone has to own the shares issued by the firm; not all buyers can lend their shares." In our model, an inability of would-be borrowers and lenders of stock to instantly locate each other implies that rational agents may indeed pay a price that is inflated by lending fees and nevertheless not lend right away. Whether lending fees, in practice, are large enough to justify observed prices is difficult to assess directly, because of the stylized nature of our model and because of difficulties in measuring agents' private valuations. Some buyers of Palm (and, presumably, spinoffs in other negative-stub-value cases) were retail investors, who do not normally benefit directly from the lending of their 


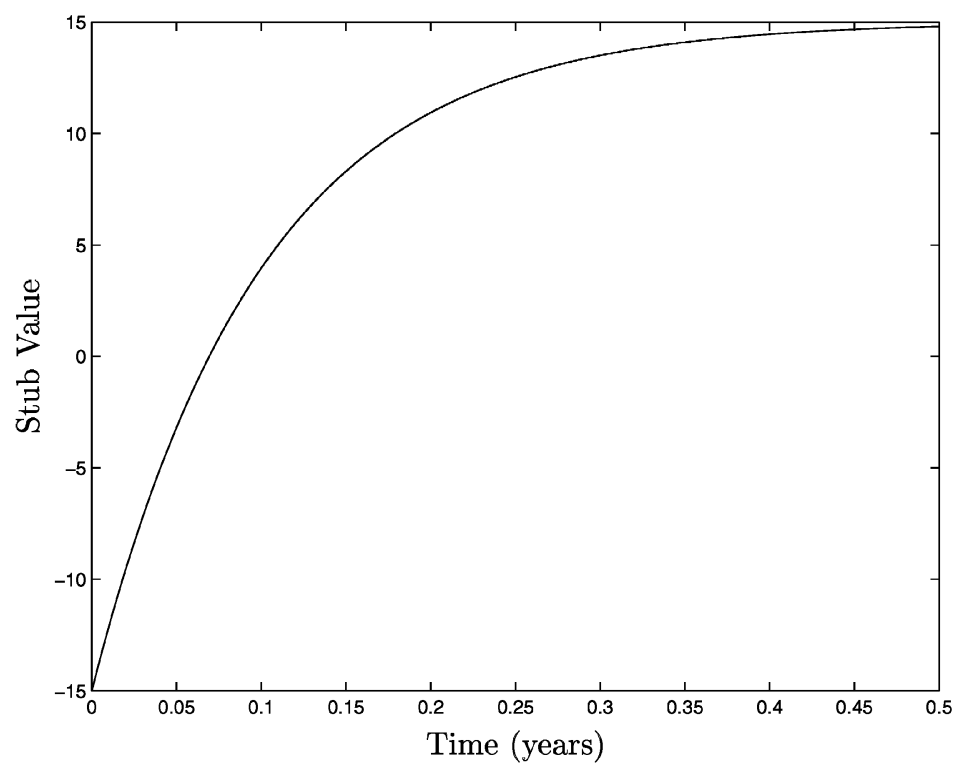

Fig. 9. The stub value, initially negative, becomes positive.

shares. Lamont and Thaler (2001) conclude, in this situation ${ }^{29}$ that such investors are irrational to buy the spin-off in a negative-stub-value situation, while Scheinkman and Xiong (2001) suggest an explanation based on speculation.

\section{Concluding remarks}

We have provided a framework for the price impact of the practice of shorting. Taking explicitly into account the potentially time-consuming nature of establishing short positions, we captured the price effect of more and more agents expressing their opinions via trading, and how lending fees are determined and incorporated into the price. We show that, in some special cases - characterized by a small float of the asset relative to the demands for shorting and for buying the asset, a large discrepancy between the beliefs of optimists and pessimists regarding the company's value, or high lender bargaining power - the effect can be strong enough to push the price of the asset above the valuation of the most optimistic among investors. An implication is that a project may, under conditions, be financed by issuing a lendable traded security, even though everyone thinks that it has a negative net present value. Further, the results show that the common wisdom that easier access to shorting reduces the price need not be true. We also illustrate how negative stub values can arise from the effect of lending fees.

\footnotetext{
${ }^{29}$ They argue that the risk of a failure to distribute the Palm shares, and certain other risks to an shorter, were small.
} 
While this paper concentrates on the price behavior of recently offered equities, the results can be reinterpreted in the context of repo specials and the valuation of corporate and government bonds, and in the context of convenience yields and the valuation of commodities. One can also investigate "bubbles" within this framework. One could easily extend our model to incorporate partial information revelation over time, the updating (and perhaps convergence) of beliefs, new agents arriving over time, disagreement among agents over the implications of new pieces of information, and fluctuations in the float and in the ease with which agents of various types are located. Other potential extensions could allow for private information (for example, concerning some market characteristics) and for hedging motives to short.

\section{Appendix A. Walras equilibrium}

In this section we derive, as a benchmark, prices and lending fees in an economy with a shorting-through-securities-lending institution, but with no search frictions. To be consistent with Section 3, we assume that agents can be long or short at most one share, and that only type- 0 agents can short. (If everyone can shortsell, the analysis is analogous.) The equilibrium price in this model is called the "Walrasian price."

At any time, an agent can instantly buy or shortsell shares, and can also lend or borrow shares. In order to shortsell $x$ shares, an agent must borrow at least $x$ shares. To lend $x$ shares, an agent must own at least $x$ shares.

Let $x(\sigma)$ be the (signed) number of shares owned by an agent of type $\sigma$. Then, in a Walrasian equilibrium with a positive lending fee, a type- $\sigma$ agent is lending (borrowing, if negative) $x(\sigma)$ shares. This is because an agent with a long position optimally lends all his shares, and an agent with a short position optimally borrows just the number of shares he needs. Hence, equilibrium in the securities market implies market clearing, in that $\int x(\sigma) \mu(\mathrm{d} \sigma)=F$. Equilibrium, and thus market clearing, in the lending market implies that $\int x(\sigma) \mu(\mathrm{d} \sigma)=0$. Thus, in the absence of frictions, there is no equilibrium with positive lending fees if the float is positive.

Consequently, the Walrasian price at any time $t$ is the valuation of the marginal investor at that time, as characterized in the following proposition.

Proposition 12. Suppose that the float is positive $(F>0)$. Then, at any time $t$, the unique Walrasian lending fee is zero, and the essentially ${ }^{30}$ unique Walrasian price is

$$
W_{t}= \begin{cases}V^{0} & \text { if } F+\mu(\{0\})>\mu((0,1]) \text { and } t<\tau, \\ V^{\bar{\sigma}(\mu(\{0\})} & \text { if } F+\mu(\{0\}) \leqslant \mu((0,1]) \text { and } t<\tau, \\ V & \text { if } t \geqslant \tau .\end{cases}
$$

\footnotetext{
${ }^{30}$ For at most a countable set of values of $\mu(\{0\})$, there may exist an interval of Walrasian equilibrium prices. As defined in the text, $W_{t}$ is highest of these.
} 


\section{Appendix B. Proofs}

Proof of Theorem 1. Only global optimality of the strategy of agent $\sigma(t)$ to buy at $t$ for the proposed expression for $P_{t}-\mathscr{L}_{t}$ needs verification.

Let $Z^{\sigma}(s)$ be the utility that type $\sigma$ derives from the strategy of buying at $s$. Then,

$$
\begin{aligned}
Z^{\sigma(t)}(s) & =\left(V^{\sigma(t)}-P_{s}+\mathscr{L}_{s}\right) \mathrm{E}\left[1_{(s<\tau)}\right] \\
& =\mathrm{E}\left[V^{\sigma(t)} 1_{(s<\tau)}\right]-\mathrm{E}\left[V^{\sigma(\tau)} \mid s<\tau\right] \mathrm{E}\left[1_{(s<\tau)}\right] \\
& =\mathrm{E}\left[\left(V^{\sigma(t)}-V^{\sigma(t)}\right) 1_{(s<\tau)}\right] .
\end{aligned}
$$

If $s<t$, then

$$
Z^{\sigma(t)}(s)=\mathrm{E}\left[\left(V^{\sigma(t)}-V^{\sigma(\tau)}\right) 1_{(t<\tau)}\right]+\mathrm{E}\left[\left(V^{\sigma(t)}-V^{\sigma(\tau)}\right) 1_{(s<\tau \leqslant t)}\right],
$$

while if $s>t$,

$$
Z^{\sigma(t)}(s)=\mathrm{E}\left[\left(V^{\sigma(t)}-V^{\sigma(\tau)}\right) 1_{(t<\tau)}\right]-\mathrm{E}\left[\left(V^{\sigma(t)}-V^{\sigma(\tau)}\right) 1_{(t<\tau \leqslant s)}\right] .
$$

In both Eqs. (B.2) and (B.3) the first term equals $Z^{\sigma(t)}(t)$, which is the utility obtained from deciding to buy at time $t$, while the second term is negative, due to the fact that $V^{\sigma(t)}$ decreases in $t$. Consequently, the strategy of buying at $t$ is globally optimal for an agent of the type $\sigma(t)$.

Proof of Theorem 2. Since $\mathscr{B}$ solves the linear ODE

$$
\begin{aligned}
\dot{\mathscr{B}}_{t} & =-\lambda_{t}^{\mathrm{B}}\left(P_{t}-L_{t}-V^{0}\right)+\left(\gamma+\lambda_{t}^{\mathrm{B}}\right) \mathscr{B}_{t} \\
& =-\lambda_{t}^{\mathrm{B}}(1-q) G_{t}+\left(\gamma+(1-q) \lambda_{t}^{\mathrm{B}}\right) \mathscr{B}_{t},
\end{aligned}
$$

we have

$$
\mathscr{B}_{t}=\int_{t}^{\infty} \mathrm{e}^{-\gamma(s-t)} \mathrm{e}^{(1-q) \int_{t}^{s} \lambda_{z}^{\mathrm{B}} \mathrm{d} z}(1-q) \lambda^{\mathrm{B}} G_{s} \mathrm{~d} s,
$$

which is equal to (14) (via integration by parts).

Using Eqs. (5) and (13), we see that $\mathscr{L}$ solves

$$
\dot{\mathscr{L}}_{t}=-\lambda_{t}^{\mathrm{L}} q\left(G_{t}-\mathscr{B}_{t}\right)+\gamma \mathscr{L}_{t},
$$

with the solution given by Eq. (15).

The optimist will never accept a negative lending fee, whence 0 (obtained when $q=0$ ) is the minimal lending fee. To see that $q=1$ yields the maximal fees, note that $P_{t}-V^{0} \geqslant L_{t}$ is a necessary condition for the pessimist to be willing to borrow, a condition which implies that $L_{t}-\mathscr{L}_{t} \geqslant G_{t}$, whence

$$
\dot{\mathscr{L}}_{t} \geqslant-\lambda_{t}^{\mathrm{L}} G_{t}+\gamma \mathscr{L}_{t} \text {. }
$$

Now apply Gronwall's inequality to infer that

$$
\mathscr{L}_{t} \leqslant \int_{t}^{\infty} \int_{t}^{s} \lambda_{u}^{\mathrm{L}} \mathrm{d} u \Delta V_{s} \mathrm{e}^{-\gamma(s-t)} \gamma \mathrm{d} s,
$$

which is the expression for $\mathscr{L}_{t}$ corresponding to $q=1$. 
Proof of Proposition 3. We fitrst show that $G(t)-\mathscr{B}(t)$ is decreasing in $t$. This follows from the fact that $\Delta V_{t}$ is decreasing in $t$ and from

$$
\begin{aligned}
G_{t}-\mathscr{B}_{t} & =\int_{t}^{\infty} \mathrm{e}^{-(1-q) \int_{t}^{u} \lambda_{z}^{\mathrm{B}} \mathrm{d} z} \Delta V_{u} \mathrm{e}^{-(u-t) \gamma} \gamma \mathrm{d} u \\
& =\int_{0}^{\infty} \mathrm{e}^{-(1-q) \lambda F u} \Delta V_{t+u} \mathrm{e}^{-\gamma u} \gamma \mathrm{d} u,
\end{aligned}
$$

which is seen to be true because $1_{\{F+S(t)<\mu((0,1])\}}=0$ implies that $\Delta V_{t}=0$. Using this and similar arguments, one shows that $\mathscr{L}(t), L(t)$, and $P(t)$ decrease in $t$.

It is clear from Eq. (3) that $S(t)$ is increasing and that $S^{\prime}(t)$ is decreasing.

Proof of Proposition 4. If there is an increase in the difference of opinions between optimists and pessimists, then $\Delta V_{t}$ increases for all $t$. Hence, from (B.10), $G_{t}-\mathscr{B}_{t}$ increases. This implies that $L$ and $\mathscr{L}$ increase.

If the difference of opinions increases, keeping $V^{0}$ constant, then $V^{\sigma(t)}$ increases for all $t$. Then, Proposition 1 shows that $P_{t}$ increases.

Proof of Proposition 5. Increasing the float increases $S_{t}$ for all $t$, which decreases $V^{\sigma(t)}, \Delta V_{t}$, and $\lambda_{t}^{L}$. Hence, using Eq. (B.10), $G_{t}-\mathscr{B}_{t}$ decreases. Using Eq. (15), we see that $\mathscr{L}_{t}$ decreases. Finally, $P_{t}$ is seen to decrease using Proposition 1.

It is obvious that $G_{t}-\mathscr{B}_{t}$ increases in $q$, and all the statements about the impact of $q$ follow immediately.

Proof of Proposition 6. Increasing $\lambda$ and $\mu(\{0\})$ increases $S_{t}$ for all $t$, which decreases $V^{\sigma(t)}$. Hence, the results follow from Eq. (8).

Proof of Proposition 7. From Eq. (B.10), it follows by dominated convergence that $G_{t}-\mathscr{B}_{t} \rightarrow 0$ as $\lambda \rightarrow \infty$, for all $t$. Note now that

$$
\mathscr{L}_{0} \leqslant\left(G_{0}-\mathscr{B}_{0}\right) \int_{0}^{\infty} \lambda_{t}^{\mathrm{L}} \mathrm{d} t
$$

where the integral is the expected number of times a given asset is lent, which is finite (in fact, it equals $\beta$ as defined in the text). The statements about $L_{t}$ and $P_{t}$ follow immediately.

Proof of Proposition 8. When $q=1$, we have $\mathscr{B}=0$, and the limit of $G_{t}$ is $\Delta V_{\infty}$. All the statements are immediate.

Proof of Proposition 9. It is clear from Eq. (14) that $\mathscr{B}_{t}$ decreases in $t$. We next show that $\mathscr{B}_{t}$ approaches zero as $\mu(\{0\})$ approaches infinity. For $\mu(\{0\})>\mu((0,1])-F$, we let $T(\mu(\{0\}))=\inf \{t: F+S(t)=\mu((0,1])\}$. From (3), we see that $T(\mu(\{0\})) \rightarrow 0$ as 
$\mu(\{0\}) \rightarrow \infty$. Now, since $\Delta V_{t}=0$ for $t \geqslant T(\mu(\{0\}))$, we see from (14) that $\mathscr{B}_{t} \rightarrow 0$ as $\mu(\{0\}) \rightarrow \infty$ for all $t \geqslant 0$.

Inspection of Eq. (14) reveals that $\Delta V_{u}$ is the only term depending on $\mu(\{0\})$. We note that $V^{\sigma(u)}=V^{\bar{\sigma}(S(u))}$ is a decreasing function of $S(u)$ which, in turn, is an increasing and continuous function of $u$ and $\mu(\{0\})$. Let $k(u)=\left(1-\mathrm{e}^{-(1-q) \lambda F u}\right) \mathrm{e}^{-u \gamma} \gamma, f$ be the function defined by $V^{\sigma(u)}=f(F+S(u))$, and $g(u, \mu(\{0\}))=F+S(u, \mu(\{0\}))$, using obvious notation from this point to indicate dependence on $\mu(\{0\})$. Let $h$ be defined by $h(u)=g\left(u, \mu_{0}\right)$. For any $T>0$ (sufficiently large) and $\Delta \mu$ (sufficiently small) let $u_{1}$ and $u_{2}$ satisfy $h\left(u_{1}\right)=A \Delta \mu$, respectively $h\left(T-u_{2}\right)=T-A \Delta \mu$, where $A$ is the modulus of continuity of $g(u, \mu)$ as a function of $\mu$, uniformly in $u$. Note that

$$
\begin{aligned}
& \mathscr{B}\left(0, \mu_{0}\right)-\mathscr{B}\left(0, \mu_{0}+\Delta \mu\right) \\
&=\int_{0}^{\infty} k(u)\left(f\left(g\left(u, \mu_{0}\right)\right)-f\left(g\left(u, \mu_{0}+\Delta \mu\right)\right)\right) \mathrm{d} u \\
& \leqslant\left.\int_{0}^{\infty} k(u)\left(f\left(g\left(u, \mu_{0}\right)\right)-f\left(g\left(u, \mu_{0}\right)+A \Delta \mu\right)\right)\right) \mathrm{d} u \\
&= \int_{0}^{u_{1}} k(u) f(h(u)) \mathrm{d} u \\
&+\int_{u_{1}}^{T-u_{2}} f(h(u))\left(k(u)-k\left(h^{-1}(h(u)-A \Delta \mu)\right)\right) \mathrm{d} u \\
&-\int_{T-u_{2}}^{T} k(u) f(h(u)+A \Delta \mu) \mathrm{d} u \\
&+\int_{T}^{\infty} k(u)\left(f\left(g\left(u, \mu_{0}\right)\right)-f\left(g\left(u, \mu_{0}\right)+\Delta \mu\right)\right) \mathrm{d} u .
\end{aligned}
$$

(The inequality owes to the monotonicity of $f$.)

Choosing $T$ large enough will make the last term arbitrarily small. A small enough $\Delta \mu$ combined with continuity makes the other three terms arbitrarily small. Consequently, $\mathscr{B}(0)$ is continuous in $\mu(\{0\})$, and so is $\mathscr{B}(t)$, by essentially the same proof.

Given that $\Delta V_{u}$ is decreasing in $\mu(\{0\}), \mathscr{B}(0)$ is strictly decreasing in $\mu(\{0\})$ if and only if there exists $u$ at which $\Delta V_{u}$ is continuous and decreases strictly in $\mu(\{0\})$. Note first that, if $\Delta V_{u}\left(\mu_{0}\right)$ decreases in $\mu(\{0\})$, then, for any $\mu_{0}^{\prime}>\mu_{0}$, defining $u^{\prime}$ so that $\Delta V_{u}\left(\mu_{0}\right)=\Delta V_{u^{\prime}}\left(\mu_{0}^{\prime}\right)$ implies that $\Delta V_{u^{\prime}}\left(\mu_{0}^{\prime}\right)$ increases in $\mu(\{0\})$ at $\mu_{0}^{\prime}$. Second, note that, if $\bar{\sigma}$ decreases strictly around 0 , then $\Delta V_{u}$ decreases around $\mu(\{0\})=0$.

Proof of Proposition 10. Increasing the difference of opinions increases $\Delta V_{t}$ for all $t$, which increases $\mathscr{B}$, as is seen from Eq. (14).

Proof of Proposition 11. It suffices to consider only times $t$ for which $F+S_{t}<\mu((0$, 1]). Note from Eqs. (21) and (22) that

$$
S^{\prime}(t)=\lambda(F+S(t-\theta)-S(t)(\mu(\{0\})-S(t)),
$$

under the assumptions that $S_{t}=0$ for all $t \leqslant 0$ and $A_{0}=F$. 
Let now $\theta_{1}<\theta_{2}$ and note that $S_{\theta_{1}}(t)=S_{\theta_{2}}(t)$ for $t \leqslant \theta_{1}$, and that $S_{\theta_{1}}^{\prime}\left(\theta_{1}\right)=S_{\theta_{2}}^{\prime}\left(\theta_{1}\right)$ and $S_{\theta_{1}}^{\prime \prime}\left(\theta_{1}\right)>S_{\theta_{2}}^{\prime \prime}\left(\theta_{1}\right)$, where $S^{\prime \prime}$ denotes the second derivative from the right (that is, the derivative from the right of $S^{\prime}$ ). The latter two relations imply that, for $t>\theta_{1}$ sufficiently close to $\theta_{1}, S_{\theta_{1}}(t)>S_{\theta_{2}}(t)$. Assume, in order to get a contradiction, that the (closed) set $\left\{t>\theta_{1}: S_{\theta_{1}}(t)=S_{\theta_{2}}(t)\right\}$ is not empty and let $t_{0}$ be its smallest element. Then, $S_{\theta_{1}}^{\prime}\left(t_{0}\right)>S_{\theta_{2}}^{\prime}\left(t_{0}\right)$, since $S_{\theta_{1}}\left(t-\theta_{1}\right)>S_{\theta_{1}}\left(t-\theta_{2}\right) \geqslant S_{\theta_{2}}\left(t-\theta_{2}\right)$, contradicting the definition of $t_{0}$.

\section{Appendix C. Parametric example}

Here are the formulae for the equlibrium quantities in the context of Section 3.5.

The short interest is $S_{t}=\mu(\{0\})\left(1-\mathrm{e}^{-\lambda F t}\right)$, and an optimist's meeting intensity of a borrower is $\lambda_{t}^{\mathrm{L}}=\lambda \mu(\{0\}) \mathrm{e}^{-\lambda F t}$. Letting $f=\mu((0,1]) /\left(V^{1}-V^{0}\right)$ be the density function of the optimists' valuations, the marginal investor valuation is $V^{\sigma(t)}=V^{1}-\left(F+S_{t}\right) / f$. By integrating against the density of the arrival time $\tau$, one computes

$$
\mathrm{E}\left(V^{\sigma(\tau)} \mid t<\tau\right)=V^{1}-\frac{F+\mu(\{0\})}{f}+\mathrm{e}^{-\lambda F t} \frac{\mu(\{0\}) \gamma}{\gamma+\lambda F} .
$$

Since $G-\mathscr{B}$ solves the differential equation

$$
\frac{\mathrm{d}}{\mathrm{d} t}\left(G_{t}-\mathscr{B}_{t}\right)=-\gamma \Delta V_{t}+(\gamma+(1-q) \lambda F)\left(G_{t}-\mathscr{B}_{t}\right),
$$

one gets

$$
\begin{aligned}
G_{t}-\mathscr{B}_{t} & =\int_{t}^{\infty} \mathrm{e}^{-(\gamma+(1-q) \lambda F)(u-t)} \gamma \Delta V_{u} \mathrm{~d} u \\
& =\frac{\gamma}{\gamma+(1-q) \lambda F}\left(V^{1}-V^{0}-\frac{F+\mu(\{0\})}{f}\right) \\
& +\frac{\gamma}{\gamma+(2-q) \lambda F} \frac{\mu(\{0\})}{f} \mathrm{e}^{-\lambda F t} .
\end{aligned}
$$

It is easily seen that

$$
\begin{aligned}
G_{t} & =\int_{t}^{\infty} \mathrm{e}^{-\gamma(u-t)} \Delta V_{u} \mathrm{~d} u \\
& =\left(V^{1}-V^{0}-\frac{F+\mu(\{0\})}{f}\right)+\frac{\mu(\{0\})}{f} \frac{\gamma}{\gamma+\lambda F} \mathrm{e}^{-\lambda F t},
\end{aligned}
$$

whence $\mathscr{B}_{t}$ is obtained immediately.

Finally, from Eq. (13),

$$
\mathscr{L}_{t}=\mathrm{e}^{-\lambda F t}\left(a+b \mathrm{e}^{-\lambda F t}\right),
$$

where

$$
a=\frac{q \lambda \mu(\{0\})}{\gamma+\lambda F}\left(V^{1}-V^{0}-\frac{F+\mu(\{0\})}{\gamma+(1-q) \lambda F}\right),
$$




$$
b=\frac{q \lambda \mu(\{0\})}{\gamma+2 \lambda F} \frac{\mu(\{0\})}{f} \frac{\gamma}{\gamma+(2-q) \lambda F} .
$$

The price, $P_{t}$, as well as $L_{t}$ and $R_{t}$, are calculated immediately, using Eqs. (9), (13), (17).

\section{References}

Aitken, M., Frino, A., McCorry, M., Swan, P., 1998. Short sales are almost instantaneously bad news: evidence from the Australian stock exchange. Journal of Finance 53, 2205-2223.

Apfel, R., Parsons, J., Schwert, W., Stewart, G., 2001. Short sales, damages and class certification in 10b-5 actions. NBER Working Paper 8618.

Asquith, P., Meulbroek, L., 1996. An empirical investigation of short interest. Unpublished working paper, Harvard Business School.

Binmore, K., Rubinstein, A., Wolinsky, A., 1986. The Nash bargaining solution in economic modelling. Rand Journal of Economics 17, 176-188.

Brav, A., Geczy, C., Gompers, P.A., 2000. Is the abnormal return following equity issuances anomalous. Journal of Financial Economics 56, 209-249.

Brent, A., Morse, D., Stice, E.K., 1990. Short interest: explanations and tests. Journal of Financial and Quantitative Analysis 25, 273-289.

Danielson, B., Sorescu, S., 2001a. Short-sale constraints and overvaluation. Unpublished working paper, University of Houston.

Danielson, B., Sorescu, S., 2001b. Why do option introductions depress stock prices? A study of diminishing short sale constraints. Journal of Financial and Quantitative Analysis 36, 451-484.

D'Avolio, G., 2001. The market for borrowing stock. Unpublished working paper, Harvard University.

Dechow, P.M., Hutton, A.P., Meulbroek, L., Sloan, R.G., 2001. Short-sellers, fundamental analysis and stock returns. Journal of Financial Economics 61, 77-106.

DeLong, J.B., Shleifer, A., Summers, L.H., Waldmann, R.J., 1990. Noise trader risk in financial markets. Journal of Political Economy 98, 703-738.

Diamond, D., Verrecchia, R.E., 1987. Constraints on short-selling and asset price adjustment to private information. Journal of Financial Economics 18, 277-311.

Duffie, D., 1996. Special repo rates. Journal of Finance 51, 493-526.

Duffie, D., Gârleanu, N., Pedersen, L.H., 2000. Valuation in dynamic bargaining markets. Unpublished working paper, Graduate School of Business, Stanford University.

Eckbo, E., Norli, O., 2001. Leverage, liquidity, and long-run IPO returns. Unpublished working paper, Amos Tuck School of Business Administration, Dartmouth College.

Figlewski, S., 1981. The informational effects of restrictions on short sales: some empirical evidence. Journal of Financial and Quantitative Analysis 16, 463-476.

Figlewski, S., Webb, G., 1993. Options, short sales, and market completeness. Journal of Finance 48, 761-777.

Geczy, C.C., Musto, D.K., Reed, A.V., 2001. Stocks are special too: an analysis of the equity lending market. Unpublished working paper, Wharton School, University of Pennsylvania.

Harrison, J.M., Kreps, D.M., 1978. Speculative investor behavior in a stock market with heterogeneous expectations. Quarterly Journal of Economics 92, 323-336.

Jarrow, R., 1980. Heterogeneous expectations, restrictions on short sales, and equilibrium asset prices. Journal of Finance 35, 1105-1113.

Jennings, R., Starks, L., 1986. Earnings announcements, stock price adjustment, and the existence of option markets. Journal of Finance 41, 107-125.

Jones, C.M., Lamont, O.A., 2001. Short sales constraints and stock returns. Unpublished working paper, Columbia University.

Kreps, D., 1990. A Course in Microeconomic Theory. Princeton University Press, Princeton, NJ. 
Krishnamurthy, A., 2001. The bond/old-bond spread. Unpublished working paper, Kellogg School of Management, Northwestern University.

Lamont, O.A., Thaler, R.H., 2001. Can the market add and subtract? Mispricing in tech stock carve-outs. Unpublished working paper, The University of Chicago.

Lintner, J., 1969. The aggregation of investor's diverse judgements and preferences in purely competitive strategy markets. Journal of Financial and Quantitative Analysis 4, 347-400.

Loughran, T., Ritter, J.R., 1995. The new issues puzzle. Journal of Finance 50, 23-51.

MacDonald, J.G., Baron, D.C., 1973. Risk and return on short positions in common stocks. Journal of Finance 28, 97-107.

Miller, E.M., 1977. Risk, uncertainty, and divergence of opinion. Journal of Finance 32, 1151-1168.

Mitchell, M., Pulvino, T., Stafford, E., 2002. Limited arbitrage in equity markets. Journal of Finance 57, 551-584.

Morris, S., 1995. The common prior assumption in economic theory. Economics and Philosophy 11, 227-253.

Morris, S., 1996. Speculative investor behavior and learning. Quarterly Journal of Economics 111, 1111-1133.

Nash, J.F., 1950. The bargaining problem. Econometrica 18, 155-162.

Ofek, E., Richardson, M., 2001. Dotcom mania: a survey of market efficiency in the internet sector. Unpublished working paper, Stern School of Business, New York University.

Protter, P., 1990. Stochastic Integration and Differential Equations. Springer, New York.

Ritter, J.R., 1991. The long run performance of initial public offerings. Journal of Finance 46, 3-28.

Safieddine, A., Wilhelm, W., 1996. An empirical investigation of short-selling activity prior to seasoned equity offerings. Journal of Finance 51, 729-749.

Scheinkman, J., Xiong, W., 2001. Overconfidence, short-sale constraints, and bubbles. Unpublished working paper, Princeton University.

Scholes, M.S., Wolfson, M.A., 1989. Decentralized investment banking: the case of discount dividendreinvestment and stock-purchase plans. Journal of Financial Economics 24, 7-35.

Senchack, A.J., Starks, L.T., 1993. Short-sale restrictions and market reaction to short-interest announcements. Journal of Financial and Quantitative Analysis 28, 177-194.

Seneca, J.J., 1967. Short interest: bearish of bullish? Journal of Finance 22, 67-70.

Shleifer, A., Summers, L.H., 1990. The noise trader approach to finance. Journal of Economic Perspectives 4, 19-33.

Shleifer, A., Vishny, R.W., 1997. Limits of arbitrage. Journal of Finance 52, 35-55.

Skinner, D.J., 1990. Options markets and the information content of accounting earnings releases. Journal of Accounting and Economics 13, 191-211.

Trejos, A., Wright, R., 1995. Search, bargaining, money, and prices. Journal of Political Economy 103, 118-140.

Woolridge, J., Dickinson, A., 1994. Short selling and common stock prices. Financial Analysts Journal 50, 20-28. 